« Static and Dynamic Effects of Central Bank Transparency "

\author{
$\underline{\text { Auteurs }}$ \\ Meixing Dai \\ Document de Travail nº 2012 - 08
}

Juillet 2012

Faculté des sciences économiques et de gestion

Pôle européen de gestion et d'économie (PEGE) 61 avenue de la Forêt Noire F-67085 Strasbourg Cedex

Secétariat du BETA Géraldine Manderscheidt Tél. : (33) 0368852069 Fax : (33) 0368852070 g.manderscheidt@unistra.fr www.beta-umr7522.fr 


\title{
Static and Dynamic Effects of Central Bank Transparency
}

\author{
Meixing Dai ${ }^{*}$
}

\begin{abstract}
Using a New Keynesian framework, this paper shows that, under optimal discretion and optimal pre-commitment in a timeless perspective, imperfect transparency about the relative weight that the central bank assigns to output-gap stabilization generally reduces the average reaction of inflation to inflation shocks and the volatility of inflation, but increases these of the output gap in static and dynamic terms, and more so when inflation shocks are highly persistent. On balance, when inflation shocks are not excessively persistent, opacity could improve social welfare, more likely under pre-commitment than under discretion, if the weight assigned to output-gap stabilization is low.
\end{abstract}

Keywords: Central bank transparency (opacity), macroeconomic volatility, inflation expectations dynamics, speed of convergence to the equilibrium.

JEL Classification: E52, E58.

\footnotetext{
*University of Strasbourg, BETA, 61, avenue de la Forêt Noire - 67085 Strasbourg Cedex-France. Phone: (+33) 03688521 31; Fax: (+33) 03688520 71; e-mail: dai@unistra.fr.
} 


\section{Introduction}

Since the seminal work of Cukierman and Meltzer (1986), the issues of central bank transparency have been largely examined in all its aspects across different types of models. Theoretical and empirical studies show that central bank transparency is in general desirable because it can improve private inflation expectations, leading to better economic decisions and thus higher social welfare, even though opacity could be desirable in the presence of large distortions. ${ }^{1}$ In practice, more and more central banks, abandoning the tradition of secrecy since the middle-1990s, are adopting higher and higher standards in political, economic, procedural, policy and operational transparency. ${ }^{2}$

This trend is closely related to the move towards more central bank independence across the world. Improved transparency, by increasing the accountability and hence enhancing the public support for central bank independence, is likely to reduce political influence over monetary policy. In this context, the rise of New Keynesian models emphasizing the importance of forward-looking expectations in the transmission mechanism of monetary policy reinforces the perception among economists and central bankers that transparency can potentially improve the anchoring of inflation expectations and therefore the trade-off between inflation and output-gap stabilization.

In the New Keynesian framework, the public's expectation about the future path of monetary policy becomes an important determinant of current economic conditions, with important implications for central bank transparency. In this framework, considering monetary delegation issues, Walsh (2003a) has shown that the optimal inflation target weight is decreasing in the variance of the target around inflation adjusted for cost shocks. Jensen

\footnotetext{
${ }^{1}$ The literature on central bank transparency is related to the broad literature on the issue of monetary uncertainty first emphasized by the important contribution of Brainard (1967). For a recent survey of the literature on central bank transparency, see Blinder et al. (2008), Crowe and Meade (2008), Geraats (2009), Dincer and Eichengreen (2007, 2010), and Eijffinger and van der Cruijsen (2010).

${ }^{2}$ This corresponds to the five motives for central bank transparency defined in Geraats (2002).
} 
(2002) finds that transparency about a control error may be disadvantageous if the central bank enjoys low-inflation credibility, and there is need for active monetary stabilization policy. In Eijffinger and Tesfaselassie (2007), if the central bank's targets are common knowledge, disclosure of the central bank's private information about future shocks impairs stabilization of current inflation and output. Walsh (2007a) shows that more-accurate central bank forecasts of demand (cost) shocks reduce (increase) optimal transparency about shortrun targets. Under optimal discretion, Westelius (2009) proves that, when the degree of persistence of an output target shock is the central bank's private information, perfect transparency amplifies the dynamic adjustments of inflation and the output gap and unambiguously increases inflation and output volatility, reducing thus welfare. Examining the optimal combination of central bank independence and conservatism, Hefeker and Zimmer (2011a) conclude that uncertain central bank preferences imply that full independence is no longer optimal. Li et al. (2010) suggest that transparency about the central bank's preference for model robustness could actually reduce macroeconomic volatility. While an inflation targeting regime with non-linear contract might provide some incentives for the central bank to be opaque about its preference for the model robustness in order to become more independent vis-à-vis the government, this is not the case with optimal linear inflation contract (Dai and Spyromitros, 2010, 2012).

This paper contributes to the literature on central bank transparency by examining the static and dynamic effects of transparency about the central bank's preferences under optimal discretion and pre-commitment in a standard New-Keynesian model. The current consensus obtained in the Barro-Gordon framework is that imperfect transparency about central bank preferences has no significant effect on the average inflation and output gap and will increase inflation and output-gap volatility (Geraats, 2002). However, while it is common to see many 
central banks announcing their inflation target, there is, to our knowledge, no central bank having produced a public statement clarifying the weights that it puts on its objectives.

Knowledge of the relative weight assigned to the output-gap target is essential for evaluating how quickly the central bank plans to steer the economy back to the inflation target following a cost shock. The larger is this weight, the longer the time period allowed by the central bank to get back to the inflation target, and correspondingly the smaller is the volatility of output. Therefore, part of the opacity regarding the central bank's objectives might be explained by the fact that, in New Keynesian models, inflationary expectations affect current pricing decisions, inciting a flexible inflation targeter with a non-negligible flexibility parameter to appear less flexible than he really is.

According to Cukierman (2009), one reason explaining this lack of transparency is the difficulty of agreeing once and for all on a value of these parameters representing the median or average position of the committee, and the risk of dissents among committee members who collectively make monetary policy decisions; another one is the formidable task involved in precise measurement of potential output and the output gap that enters the loss function, which may lead the policymaker (even a unitary policymaker) to shy away from formulating a precise value for preference parameters.

The main objective of the paper is to show if the static and dynamic effects of uncertain central bank preferences in a standard New Keynesian framework emphasizing forwardlylooking expectations could account for such behaviors of central bankers. Our study helps to understand the difference of effects of central bank transparency across economic models. It is particularly interesting because, according to Cukierman (2002), central banks and economic agents are submitted to important model uncertainty.

Our main results suggest that imperfect transparency about the central bank preference parameters could be welfare improving in static and dynamic terms if the central bank assigns 
a relative low weight to output-gap stabilization. This result echoes with these of Westelius (2009) obtained in the standard New Keynesian framework, showing that imperfect transparency about the central bank's targets could simultaneously reduce the volatility of inflation and the output gap and moderate their dynamic adjustments. Our results are not contradictory with recent empirical studies (Demertzis and Hughes Hallet, 2007; Geraats, 2009; Dincer and Eichengreen, 2007 and 2010; van der Cruijsen et al., 2010; Spyromitros and Tuysuz, 2012), which, while in most cases showing the positive effect of transparency on macroeconomic performance, do not go far enough, due to lack of data, so as to appreciate the effects of uncertainty about the relative weight that central banks assign to output-gap stabilization.

The present study is closely related to the works of Nolan and Schaling (1998), Eijffinger et al. (2000), Faust and Svensson (2001), Jensen (2003), and Demertzis and Hughes Hallet (2007) among others. Using the static Barro-Gordon framework, they show that imperfect transparency about central bank preferences is detrimental to social welfare when corrections are made for the effects due to arbitrary specifications of uncertainty about one or the other parameter attached to the central bank's objectives. Of great relevance to this paper, with regard to its theoretical conclusions, are models introducing distortions through the wage setting behavior of labor unions (e.g.. Sorensen, 1991; Grüner, 2002, Spyromitros and Zimmer, 2006), or distortionary taxes (Hughes Hallett and Viegi, 2003; Ciccarone et al., 2007; Hefeker and Zimmer, 2011b), or/and public investment (Dai and Sidiropoulos, 2011). In models with distortions, central bank opacity could improve welfare because it could discipline the private sector or the government when setting wages or tax rates.

The remainder of the paper is organized as follows. In the next section, we present the basic model. In the section after, we solve the model under discretion and examine the effects of opacity about central bank preferences on the level and volatility of macroeconomic 
variables and the dynamics of inflation expectations. In section 4, we investigate the same issues when the monetary policy is conducted under optimal pre-commitment in a timeless perspective. Section 5 compares the static and dynamic effects of opacity under these two policy regimes. The last section concludes.

\section{The model}

The description of the economic environment follows the standard New-Keynesian model based on optimizing private sector behaviour and nominal rigidities that has been extensively used in the recent literature on monetary policy (Clarida et al. 1999). The economy is characterized by a forward-looking Phillips curve:

$$
\pi_{t}=\beta \mathrm{E}_{t} \pi_{t+1}+\delta x_{t}+e_{t}, \quad \text { with } 0<\beta<1, \delta>0
$$

where $\pi_{t}$ is the inflation rate, $\mathrm{E}_{t} \pi_{t+1}$ the private sector's expectation of future inflation, $x_{t}$ the output gap, $e_{t}$ an inflation or cost-push shock. $\beta$ is the household's subjective discount factor, which is positive but less than unity. The composite parameter $\delta$ is the output-gap elasticity of inflation and captures the effects of the gap on real marginal costs and marginal cost on inflation. More precisely, $\delta \equiv \frac{(1-\vartheta)(1-\vartheta \beta)}{\vartheta}(1+\varphi)$, where $\vartheta$ is the fraction of firms keeping their prices constant in period $t$, and $(1+\varphi)$ characterizes the linear relation between the real marginal costs and the output gap.

We assume that the inflation shock is serially correlated and follows an $\mathrm{AR}(1)$ process:

$$
e_{t}=\rho e_{t-1}+v_{t}, \quad 0 \leq \rho \leq 1 \text { and } \mathrm{E}_{t-1} v_{t}=0 ;
$$

where $v_{t}$ has a zero mean and is serially uncorrelated, and $\rho$ represents the degree of persistence of inflation shocks. 
In an economy characterized by equation (1), monetary policy affects current inflation and the output gap through two channels. The first is the policy rule (or direct) channel. In effect, the implied price inertia of the model enables monetary authorities to manipulate the real interest rate through the variation in the nominal interest rate, affecting the aggregate demand, and hence inflation and the output gap. The second is the inflation expectations (or indirect) channel. Acknowledging that monetary policy affects the expected future stream of output gaps and inflations, some firms will modify their prices today in anticipating that they may be unable to adjust prices in the future, causing current inflation to vary.

Because the forward-looking property of the New Keynesian Phillips curve is a very important channel for monetary policy, it is also essential for the impact of political transparency. The standard Barro-Gordon framework, which is largely used in the literature on the central bank transparency, only allows analyzing the direct and indirect effects of transparency in the conduct of current monetary policy, but does not capture the effects of transparency operating through the public's perception of future policy. This perception is dynamic by nature and cannot be elicited in the Barro-Gordon model.

It is therefore insightful to examine the implications of such a perception for political transparency in Clarida et al. (1999) when the issue of transparency is addressed by use of the CB's objective function employed in the traditional literature on transparency. The central bank is assumed to minimize a standard objective function which is quadratic in deviations of inflation and the output gap from their respective zero target levels:

$$
L^{C B}=\frac{1}{2} \mathrm{E}_{t} \sum_{i=0}^{\infty} \beta^{i}\left[(\lambda-\varepsilon) x_{t+i}^{2}+(1+\varepsilon) \pi_{t+i}^{2}\right], \quad \lambda>0,
$$

where $\lambda$ is the expected relative weight placed on the output-gap objective, $\beta$ the central bank's discount factor. The weights assigned by the central bank to inflation and output-gap stabilization are more or less predictable by the private sector, meaning that $\varepsilon$ is a stochastic 
variable. The formulation according to which $\varepsilon$ is associated with both inflation and outputgap objectives is adopted to avoid the arbitrary effects of central bank preference uncertainty on average monetary policy (Beetsma and Jensen, 2003). The distribution of $\varepsilon$ is characterized by $\mathrm{E}(\varepsilon)=0, \operatorname{var}(\varepsilon)=\mathrm{E}\left(\varepsilon^{2}\right)=\sigma_{\varepsilon}^{2}$ and $\varepsilon \in[-1, \lambda]$. The variance $\sigma_{\varepsilon}^{2}$ represents the degree of opacity about central bank preferences. When $\sigma_{\varepsilon}^{2}=0$, the central bank is completely predictable and hence fully transparent. Knowing that the random variable $\varepsilon$ is taking values in a compact set and its expected value is equal to zero, Ciccarone et al. (2007) and Ciccarone and Marchetti (2009) have proved that $\sigma_{\varepsilon}^{2}$ has an upper bound so that $\sigma_{\varepsilon}^{2} \in[0, \lambda]$

\section{Optimal monetary policy under discretion}

The central bank is assumed to determine the optimal discretionary policy along the lines of Clarida et al. (1999). Thus, the decision problem of the central bank becomes the single period problem of choosing the values of inflation and the output gap that minimize the loss function subject to the inflation adjustment equation. The policy instrument remains the interest rate, as the Euler condition (the IS curve) imposes no constraint in the central bank's problem and can be "subsequently" used to solve for the rate of interest once optimal inflation and output gap have been determined. Therefore, we do not pay attention to the IS curve and hence the rate of interest.

The central bank implements the time-consistent discretionary monetary policy. Under discretion, the central bank treats expectations of future inflation as given in setting $\pi_{t}$. It minimizes the loss function (3) subject to the constraint (1). The first-order condition is

$$
x_{t}=-\delta \Phi \pi_{t} .
$$


where $\Phi=\frac{1+\varepsilon}{\lambda-\varepsilon}$ and its expected value is approximated using the second-order Taylor development as $\mathrm{E}_{t}(\Phi) \cong \frac{1}{\lambda}+\frac{1+\lambda}{\lambda^{3}} \sigma_{\varepsilon}^{2}$. Substituting $x_{t}$ given by (4) into (1), we obtain

$$
\mathrm{E}_{t} \pi_{t+1}=\frac{1}{\beta}\left(1+\delta^{2} \Phi\right) \pi_{t}-\frac{1}{\beta} e_{t}
$$

In the following, we will first determine the solutions of equilibrium and then examine the static and dynamic effects of central bank opacity.

\subsection{The equilibrium}

The difference equation in $\pi_{t}$ given by (5) and (23) has a unique non-explosive rational expectations solution. Known as the "minimal state variable" (MSV) solution, it can be obtained using the method of undetermined coefficients (McCallum, 1983). Given that the only state variable in this model is the exogenous cost shock $e_{t}$, we guess that the solutions of $\pi_{t}$ and $\mathrm{E}_{t} \pi_{t+1}$ take the following forms: $\pi_{t}=\zeta e_{t}$ and $\mathrm{E}_{t} \pi_{t+1}=\mathrm{E}_{t}\left(\zeta e_{t+1}\right)$. This with (2) yields $\mathrm{E}_{t} \pi_{t+1}=\rho e_{t} \mathrm{E}_{t}(\zeta)$. Substituting the latter into equation (5) and comparing the resulting solution of $\pi_{t}$ with $\pi_{t}=\zeta e_{t}$ implies $\zeta=\Theta\left[\beta \rho \mathrm{E}_{t}(\zeta)+1\right]$, whose mathematical expectations allow to obtain ${ }^{3}$

$$
\mathrm{E}_{t}(\zeta)=\frac{\mathrm{E}_{t}(\Theta)}{1-\beta \rho \mathrm{E}_{t}(\Theta)}
$$

where $\Theta \equiv \frac{\lambda-\varepsilon}{\lambda-\varepsilon+\delta^{2}(1+\varepsilon)}$. Using the second-order Taylor approximation and taking account of opacity, we obtain $\mathrm{E}_{t}(\Theta) \cong \frac{\lambda}{\lambda+\delta^{2}}-\frac{\delta^{2}(1+\lambda)\left(1-\delta^{2}\right)}{\left(\lambda+\delta^{2}\right)^{3}} \sigma_{\varepsilon}^{2}$.

Substituting $\mathrm{E}_{t}(\zeta)$ given by (6) into $\mathrm{E}_{t} \pi_{t+1}=\rho e_{t} \mathrm{E}_{t}(\zeta)$ and using (4) and (5), we get

$$
\left.\mathrm{E}_{t} \pi_{t+1}\right|_{\text {discretion }}=\frac{\rho \mathrm{E}_{t}(\Theta) e_{t}}{1-\beta \rho \mathrm{E}_{t}(\Theta)}
$$

\footnotetext{
${ }^{3}$ The appendices are available upon request.
} 


$$
\begin{aligned}
\left.\pi\right|_{\text {discretion }} & =\frac{\Theta e_{t}}{1-\beta \rho \mathrm{E}_{t}(\Theta)}, \\
\left.x_{t}\right|_{\text {discretion }} & =-\frac{\delta \Omega e_{t}}{1-\beta \rho \mathrm{E}_{t}(\Theta)},
\end{aligned}
$$

where $\Omega \equiv \frac{(1+\varepsilon)}{\lambda-\varepsilon+\delta^{2}(1+\varepsilon)}$, and the second-order Taylor approximation of its expected value is given as $\mathrm{E}(\Omega) \cong \frac{1}{\lambda+\delta^{2}}+\frac{(1+\lambda)\left(1-\delta^{2}\right)}{\left(\lambda+\delta^{2}\right)^{3}} \sigma_{\varepsilon}^{2}$.

The variances of inflation and the output gap are obtained using (8) and (9) as:

$$
\begin{aligned}
\left.\operatorname{var}\left(\pi_{t}\right)\right|_{\text {discretion }} & =\frac{\mathrm{E}_{t}\left(\Theta^{2}\right)}{\left[1-\beta \rho \mathrm{E}_{t}(\Theta)\right]^{2}} \sigma_{e}^{2}, \\
\left.\operatorname{var}\left(x_{t}\right)\right|_{\text {discretion }} & =\frac{\delta^{2} \mathrm{E}\left(\Omega^{2}\right)}{\left[1-\beta \rho \mathrm{E}_{t}(\Theta)\right]^{2}} \sigma_{e}^{2},
\end{aligned}
$$

where $\sigma_{e}^{2}=\operatorname{var}\left(e_{t}\right) . \mathrm{E}_{t}\left(\Theta^{2}\right)$ and $\mathrm{E}\left(\Omega^{2}\right)$ are respectively approximated using the secondorder Taylor development as $\quad \mathrm{E}_{t}\left(\Theta^{2}\right) \cong \frac{\lambda^{2}}{\left(\lambda+\delta^{2}\right)^{2}}+\frac{\delta^{2}(1+\lambda)\left[\delta^{2}+\lambda\left(3 \delta^{2}-2\right)\right]}{\left(\lambda+\delta^{2}\right)^{4}} \sigma_{\varepsilon}^{2} \quad$ and $\mathrm{E}\left(\Omega^{2}\right) \cong \frac{1}{\left(\lambda+\delta^{2}\right)^{2}}+\frac{(1+\lambda)\left(\lambda+3-2 \delta^{2}\right)}{\left(\lambda+\delta^{2}\right)^{4}} \sigma_{\varepsilon}^{2}$. According to (7)-(11), the central bank's political opacity affects $\mathrm{E}_{t} \pi_{t+1}, \operatorname{var}\left(\pi_{t}\right)$ and $\operatorname{var}\left(x_{t}\right)$ both through the numerator and the denominator while affecting $\pi_{t}$ and $x_{t}$ only through the denominator.

Hereafter, we will examine the effects of imperfect transparency on the equilibrium and dynamics of the economy under monetary policy discretion in distinguishing serially uncorrelated and correlated inflation shocks.

\subsection{The equilibrium effects of central bank opacity}

Central bank opacity indirectly affects the level of inflation and the output gap through its effects on inflation expectations. It affects the variance of these variables both through the 
inflation expectations (or indirect) channel and the policy rule (or direct) channel. The latter corresponds to the fact that the shocks affecting central bank preferences modify the trade-off between inflation and the output gap, i.e., the slope of the monetary policy rule given by equation (4), and hence the reactions of inflation and the output gap to inflation shocks, leading to a change of their respective volatilities. To distinguish the respective effects due to these two channels, we first consider the case of serially uncorrelated inflation shocks, where the expected future inflation is zero, and then the case of serially correlated inflation shocks.

The case of serially uncorrelated inflation shocks

This is the case where $\rho=0$, implying that $\mathrm{E}_{t}\left(e_{t}\right)=0$ and hence $\mathrm{E}_{t} \pi_{t+1}=0$. Using (8)(11), it is straightforward to obtain $\mathrm{E}_{t}\left(\frac{\partial \pi_{t}}{\partial e_{t}}\right)=\mathrm{E}_{t}(\Theta), \mathrm{E}_{t}\left(\frac{\partial x_{t}}{\partial e_{t}}\right)=\delta \mathrm{E}(\Omega), \operatorname{var}\left(\pi_{t}\right)=\mathrm{E}_{t}\left(\Theta^{2}\right) \sigma_{e}^{2}$ and $\operatorname{var}\left(x_{t}\right)=\delta^{2} \mathrm{E}_{t}\left(\Omega^{2}\right) \sigma_{e}^{2}$

Since $\mathrm{E}_{t} \pi_{t+1}=0$, the effects of imperfect transparency on the volatility of inflation and the output gap are exercised through the policy rule channel of the uncertainty about central bank preferences. The importance and the sense of such effects depend on the value of structural parameters. Examining the reactions of $\pi_{t}, x_{t}, \mathrm{E}_{t}\left(\frac{\partial \pi_{t}}{\partial e_{t}}\right), \mathrm{E}_{t}\left(\frac{\partial x_{t}}{\partial e_{t}}\right), \operatorname{var}\left(\pi_{t}\right)$ and $\operatorname{var}\left(x_{t}\right)$ to an increase in opacity leads to the following proposition.

Proposition 1. Under optimal discretion, when inflation shocks are serially uncorrelated, an increase in opacity will not affect the level of inflation and the output gap for a given preference shock but will reduce the average reaction of inflation and increases the average reaction of the output gap to inflation shocks if $\delta<1$. It will decrease the volatility of inflation if $\delta<\sqrt{\frac{2 \lambda}{1+3 \lambda}}$ and vice versa. It will increase the volatility of the output gap if $\delta<\sqrt{\frac{\lambda+3}{2}}$ and vice versa. 
Imperfect transparency does not affect inflation and the output gap through the inflation expectations channel because the expected inflation rate is always equal to zero when inflation shocks are serially uncorrelated. However, the reactions of inflation and the output gap to inflation shocks are directly affected by unpredictable preference shocks and hence their average reactions are affected by opacity through the policy rule channel. In effect, given that $\mathrm{E}_{t}\left(\frac{\partial \pi_{t}}{\partial e_{t}}\right)=\mathrm{E}_{t}(\Theta)$ and $\mathrm{E}_{t}\left(\frac{\partial x_{t}}{\partial e_{t}}\right)=-\delta \mathrm{E}_{t}(\Omega)$ and the second-order Taylor approximations of $\mathrm{E}_{t}(\Theta)$ and $\mathrm{E}_{t}(\Omega)$, it is straightforward to see that, for such effects on average inflation and output gap to disappear (or to be inversed), the output-gap elasticity of inflation $\delta$ must be equal to (or greater than) unity. According to equation (4), the optimal trade-off between inflation and the output gap must verify $(\lambda-\varepsilon) d x_{t}=-\delta(1+\varepsilon) d \pi_{t}$. The Phillips curve implies that $d x_{t}=\frac{1}{\delta} d \pi_{t}$, where $\delta$ corresponds to the rate of transformation between inflation and the output gap. Inserting the latter equation into the previous condition yields:

$$
\lambda d x_{t}=-\delta d \pi_{t}+\frac{1}{\delta}\left(1-\delta^{2}\right) \varepsilon d \pi_{t}
$$

Equation (12) illustrates why $\delta=1$ is a critical threshold. In effect, for $\delta=1$, the optimal trade-off condition (12) will be the same as in the case of full transparency and thus imperfect transparency will not affect the average equilibrium.

For $\delta<1$, the preference shocks stochastically affect the slope of the policy rule. To appreciate its average impact on the policy rule (4), we use the latter to compute $d \mathrm{E}\left(x_{t}\right)=-\delta \mathrm{E}_{t}(\Phi) d \mathrm{E}\left(\pi_{t}\right)$ where $\mathrm{E}\left(\pi_{t}\right)$ and $\mathrm{E}\left(x_{t}\right)$ represent the average value of inflation and the output gap. Given that $\frac{\partial \mathrm{E}_{t}(\Phi)}{\partial \sigma_{\varepsilon}^{2}} \cong \frac{1+\lambda}{\lambda^{3}}$, this means that an opaque central bank is ready to trade off one percent of decrease in inflation against a larger loss in output compared to a perfectly transparent central bank. In other words, the average policy rule $\left(\overline{M P}_{\varepsilon \neq 0}^{d i s}\right)$ has a slope with an absolute value lower than that of the policy rule under perfect transparency (see 
Figure 1, where $P C\left(e_{t}>0\right)$ represents the Phillips curve subject to a non-persistent positive inflation shock under opacity, while $P C\left(e_{t}=0\right)$ represents the Phillips curve in the absence of shocks; $M P_{\varepsilon=0}^{d i s}$ and $\overline{M P_{\varepsilon \neq 0}^{d i s}}$ stand for the policy rule under full transparency and the average policy rule under opacity respectively). Therefore, on average, imperfect transparency attenuates the reactions of inflation but amplifies these of the output gap to inflation shocks compared to perfect transparency (point 2 versus point 1 in the event of a positive inflation shock).

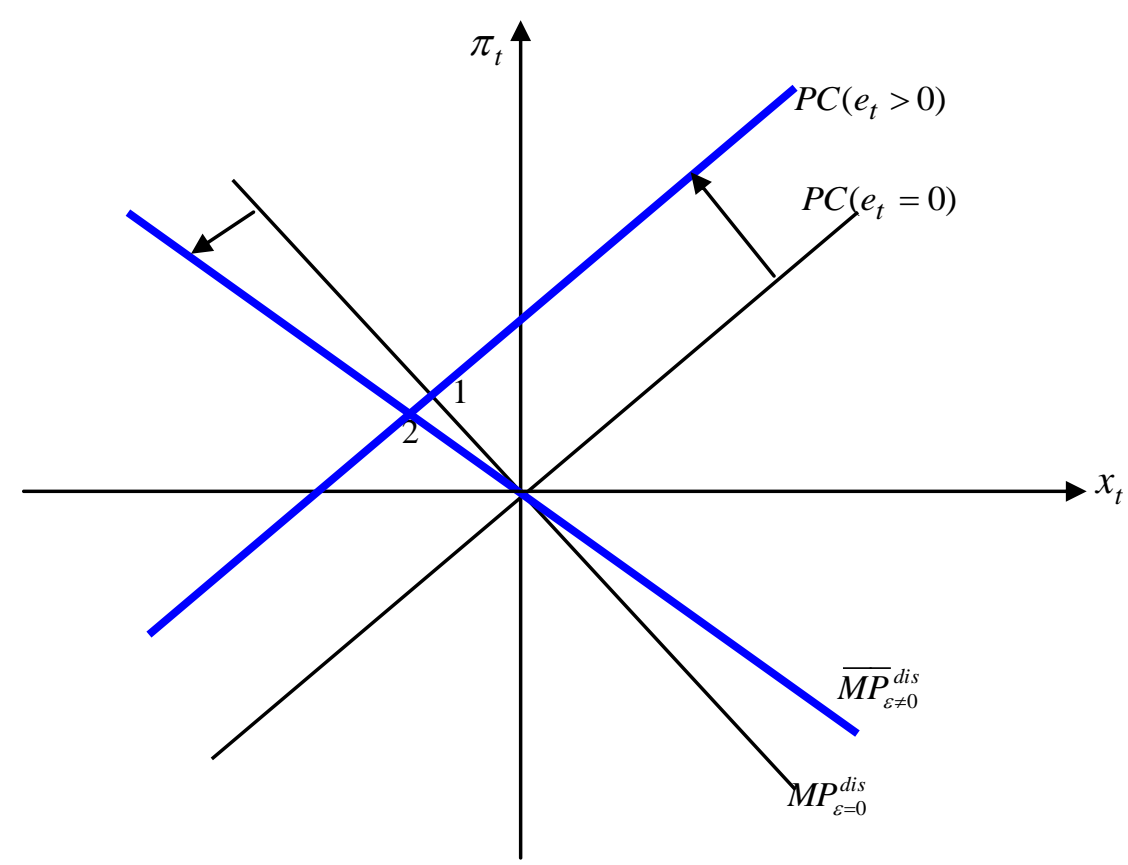

Figure 1. The effect of opacity on the equilibrium with $\rho=0$ and $\delta<1$.

The parameter $\delta$ captures both the impact of a change in real marginal cost on inflation and the co-movement of real marginal cost and the output gap. Its range of values in previous studies is quite small. For example, McCallum and Nelson (2004) characterize the empirical evidence as consistent with a value of $\delta$ in the range [0.01, 0.05] according to the estimates in Galí and Gertler (1999), Walsh (2003b) sets $\delta=0.0832$, and Westelius (2009) uses $\delta=0.03$. Roberts (1995) reports higher values, with the estimated coefficient on the output 
gap at about 0.3 , which is equivalent to $\delta=0.075$ on a quarter basis. Some researchers adopt high values for $\delta$ in their numerical simulations. For example, Jensen (2002) retains $\delta=1$, and Walsh (2007b), considering $\vartheta=0.5, \quad \beta=0.99, \quad$ and $\varphi=1$, obtains $\delta \equiv \frac{(1-\vartheta)(1-\vartheta \beta)}{\vartheta}(1+\varphi)=1.010$. If $\delta \geq 1$ is verified, the effects of opacity on average inflation and output gap through the policy rule channel will be neutralized $(\delta=1)$ or inversed $(\delta>1)$. Given the empirical studies on the New Keynesian Phillips curve reporting low values for $\delta$, these are less likely situations.

As inflation shocks are serially uncorrelated, central bank opacity will affect the volatility of inflation and the output gap only through the policy rule channel. The effects of opacity on macroeconomic volatility depend on the output-gap elasticity of inflation $(\delta)$ and the expected relative weight assigned to output-gap stabilization $(\lambda)$.

It is to notice that the condition $\delta<\sqrt{\frac{2 \lambda}{1+3 \lambda}}$ is more restrictive than $\delta<1$, while $\delta<\sqrt{\frac{\lambda+3}{2}}$ is less restrictive. To reverse the positive effect of opacity on the volatility of the output gap, one must have $\delta>\sqrt{\frac{\lambda+3}{2}}$, which is unlikely.

Given that the parameter $\delta$ is generally small, only a very low value for $\lambda$ could make possible the condition $\delta>\sqrt{\frac{2 \lambda}{1+3 \lambda}}$, allowing thus opacity to increase the volatility of inflation. The latter might not significantly increase when $\lambda$ becomes small because the degree of opacity is limited by the value of $\lambda$ according to Ciccarone et al. (2007). Nevertheless, the central bank will have a greater incentive to be more transparent if it attributes a very low value to $\lambda$ so that $\delta>\sqrt{\frac{2 \lambda}{1+3 \lambda}}$, since in this case more transparency will reduce the volatility of inflation while mitigating the volatility of the output gap. This result is consistent with the empirical observation according to which the current trend of increased transparency amongst 
central banks appears to have occurred simultaneously with an increased emphasis on price stability (Cukierman, 2002).

The case of serially correlated inflation shocks

This is the case where $0<\rho<1$. Given that the numerical values set for the parameter $\delta$ in New Keynesian models are generally very small, we consider only the case where $\delta<1$ when examining the effect of opacity on the level and volatility of inflation and the output gap. Deriving twice (8) and (9) with respect to $e_{t}$ and $\sigma_{\varepsilon}^{2}$ leads to the following proposition.

Proposition 2a. Under optimal discretion, an increase in opacity will induce a decrease in the sensitivity of inflation and the output gap to a serially correlated inflation shock, for $\delta<1$.

When inflation shocks are persistent, future expected inflation rate will be different from zero since it reflects both the implications of current inflation shocks for future inflations and the reactions of the central bank to these shocks. Using equation (7), we find that $\frac{\partial^{2} \mathrm{E}_{t} \pi_{t+1}}{\partial e_{t} \partial \sigma_{\varepsilon}^{2}}=-\frac{\rho \delta^{2}(1+\lambda)\left(1-\delta^{2}\right)}{\left[1-\beta \rho \mathrm{E}_{t}(\Theta)\right]^{2}\left(\lambda+\delta^{2}\right)^{3}}<0$, implying that an increase in central bank opacity will induce the private sector to adjust less its inflation expectations in response to the current inflation shock. This in turn will incite the central bank to reduce the responses of inflation rate (and hence the output gap) to inflation shocks. Since a high degree of persistence of inflation shocks will increase inflation expectations, it will increase the role of opacity and hence will amplify attenuation effects of a decrease in transparency on the expected inflation.

Proposition $2 \boldsymbol{b}$. Under optimal discretion, an increase in the persistence of inflation shocks reinforces the effects of central bank opacity through the inflation expectations channel on inflation and the output gap, for $\delta<1$.

The presence of serially correlated inflation shocks implies, under opacity, a weaker response of inflation and the output gap to the inflation shock for a given central bank 
preference shock if the output-gap elasticity of the inflation is lower than unity. This result is independent of the initial degree of opacity.

Deriving (8) and (9) with respect to $e_{t}$ and then the expected values of resulting derivatives with respect to $\sigma_{\varepsilon}^{2}$ yield:

$$
\begin{aligned}
& \frac{\partial \mathrm{E}\left(\frac{\partial \pi_{t}}{\partial e_{t}}\right)}{\partial \sigma_{\varepsilon}^{2}}=-\frac{\delta^{2}(1+\lambda)\left(1-\delta^{2}\right)}{\left[1-\beta \rho \mathrm{E}_{t}(\Theta)\right]^{2}\left(\lambda+\delta^{2}\right)^{3}}<0, \\
& \frac{\partial \mathrm{E}\left(\frac{\partial x_{t}}{\partial e_{t}}\right)}{\partial \sigma_{\varepsilon}^{2}}=-\frac{(1-\beta \rho) \delta(1+\lambda)\left(1-\delta^{2}\right)}{\left[1-\beta \rho \mathrm{E}_{t}(\Theta)\right]^{2}\left(\lambda+\delta^{2}\right)^{3}}<0 .
\end{aligned}
$$

Examining (13) and (14), we obtain the following propositions.

Proposition 3a. Under optimal discretion, an increase in opacity will induce a decrease in the average reaction of inflation and an increase in the average reaction of the output gap to a serially correlated inflation shock for $\delta<1$.

The marginal effects reported in Proposition 3a will be less important with the increase in the initial degree of opacity but will be amplified by an increase in the persistence of inflation shocks. In effect, an increase in the degree of persistence will induce a higher expected future inflation rate according to equation (7), implying that opacity will generally have a great role to play in reducing the expected inflation rate and hence will make a larger impact on inflation and the output gap on average.

Proposition 3b. Under optimal discretion, for $\delta<1$, an increase in the persistence of inflation shocks reinforces the attenuation effects of central bank opacity on the average reaction of inflation to inflation shocks. It will reinforce the amplification effects of opacity on the average reaction of the output gap to inflation shocks if $\rho<\frac{2 \mathrm{E}_{t}(\Theta)-1}{\beta \mathrm{E}_{t}(\Theta)}$ and vice versa.

An increase in the degree of persistence reinforces the effect of opacity on the output gap if the initial degree of persistence is sufficiently low. To ensure that the condition given in the 
proposition is verified for positive values of $\rho$, the initial degree of opacity must be sufficiently low, such that $\sigma_{\varepsilon}^{2}<\frac{\left(\lambda-\delta^{2}\right)\left(\lambda+\delta^{2}\right)^{2}}{2 \delta^{2}(1+\lambda)\left(1-\delta^{2}\right)}$, which is verified for positive $\sigma_{\varepsilon}^{2}$ only if the weight assigned to output-gap stabilization is sufficiently high, i.e. $\lambda>\delta^{2}$. In contrast, an increase in the initial degree of opacity will generally weaken the marginal effects of opacity on the average reactions of both variables to inflation shocks.

Deriving twice the variances of inflation and the output gap given by (10) and (11) with respect to $\sigma_{e}^{2}$ and $\sigma_{\varepsilon}^{2}$ yields

$$
\begin{aligned}
& \left.\frac{\partial^{2} \operatorname{var}\left(\pi_{t}\right)}{\partial \sigma_{e}^{2} \partial \sigma_{\varepsilon}^{2}}\right|_{\text {discretion }}=\overbrace{\frac{\delta^{2}(1+\lambda)\left[\delta^{2}+\lambda\left(3 \delta^{2}-2\right)\right]}{\left(\lambda+\delta^{2}\right)^{4}\left[1-\beta \rho \mathrm{E}_{t}(\Theta)\right]^{2}}}^{\text {Policy rule channel }}-\overbrace{\frac{2 \beta \rho \delta^{2}(1+\lambda)\left(1-\delta^{2}\right) \mathrm{E}_{t}\left(\Theta^{2}\right)}{\left(\lambda+\delta^{2}\right)^{3}\left[1-\beta \rho \mathrm{E}_{t}(\Theta)\right]^{3}}}^{\text {Inflationexpectations channel }}, \\
& \left.\frac{\partial^{2} \operatorname{var}\left(x_{t}\right)}{\partial \sigma_{e}^{2} \partial \sigma_{\varepsilon}^{2}}\right|_{\text {discretion }}=\overbrace{\frac{\delta^{2}(1+\lambda)\left(\lambda+3-2 \delta^{2}\right)}{\left(\lambda+\delta^{2}\right)^{4}\left[1-\beta \rho \mathrm{E}_{t}(\Theta)\right]^{2}}}^{\text {Policy rule channel }}-\overbrace{\frac{2 \beta \rho \delta^{4}(1+\lambda)\left(1-\delta^{2}\right) \mathrm{E}_{t}\left(\Omega^{2}\right)}{\left(\lambda+\delta^{2}\right)^{3}\left[1-\beta \rho \mathrm{E}_{t}(\Theta)\right]^{3}}}^{\text {Inflationexpectations channel }}
\end{aligned}
$$

In (15) and (16), the degrees of persistence and opacity interact, implying that the marginal effect of an increase in opacity will depend on the initial levels of $\rho$ and $\sigma_{\varepsilon}^{2}$. In the following, in order to obtain some clear-cut conditions, we only consider the case where the initial equilibrium is characterized by full transparency.

Proposition 4. Under optimal discretion, beginning with an initial equilibrium with full transparency, an increase in opacity will induce a lower inflation volatility if $\delta<\sqrt{\frac{2 \lambda}{1+3 \lambda}}$, $\forall \rho \in[0,1]$ or if $\sqrt{\frac{2 \lambda}{1+3 \lambda}}<\delta<1$ and $\rho>\frac{\left[\delta^{2}+\lambda\left(3 \delta^{2}-2\right)\right]\left(\lambda+\delta^{2}\right)}{\delta^{2}(1+\lambda) \lambda \beta}$. It will increase the volatility of the output gap if $\delta<1, \forall \rho \in[0,1]$.

According to equations (15) and (16), the effects of opacity through the inflation expectations channel on the variance of inflation and the output gap are negative if $\delta<1$. Under the sufficient condition $\delta<\sqrt{\frac{2 \lambda}{1+3 \lambda}}$, the effect of opacity through the policy rule 
channel on the volatility of inflation is also negative, ensuring hence that the total effects of opacity on the variance of inflation are negative. If $\sqrt{\frac{2 \lambda}{1+3 \lambda}}<\delta<1$, the direct effect of opacity on the volatility of inflation is positive. It will be dominated by the negative indirect effect if the degree of persistence of inflation shocks is sufficiently high, i.e. $\rho>\frac{\left[\delta^{2}+\lambda\left(3 \delta^{2}-2\right)\right]\left(\lambda+\delta^{2}\right)}{\delta^{2}(1+\lambda) \lambda \beta}$.

The condition $\delta<1$, while ensuring that the effect of decreased transparency through the inflation expectations channel on the volatility of the output gap is negative, implies that the effect of decreased transparency via the policy rule channel is positive. The negative indirect effect of opacity is always dominated by the positive direct effect for all $\rho \in[0,1]$.

Our results with regard to inflation expectations are consistent with the consensus in the literature on central bank transparency, according to which decreased transparency deteriorates the private sector's understanding of the central bank's objectives and actions. Thus, opacity renders expectations less responsive to current monetary policy actions. If monetary policy only affects the real economy through unanticipated policy actions, then decreased transparency may increase the effectiveness of monetary policy, by enabling the latter to surprise the public. Therefore, introducing some uncertainty about the preference parameters makes easier for monetary policy to mitigate the effect of an inflation shock on inflation and the output gap.

A higher degree of opacity decreases (increases) the costs of achieving a higher level of output-gap (inflation). It has thus smoothing effects on inflation but the opposite effects on the output gap. These effects are stronger when the trade-off between inflation and the output gap is high (i.e., when the inflation shock is more persistent and the weight assigned to output-gap stabilization is lower) than when the trade-off is low.

The results reported in Proposition 4 are quite limited by the fact that, in order to derive some analytical conditions, we assume that the initial degree of opacity is zero. More 
generally, the first term in (15) is negative if $\delta<\sqrt{\frac{2 \lambda}{1+3 \lambda}}$ and the first term in (16) is positive if $\delta<\sqrt{\frac{\lambda+3}{2}}$ while the second term in both equations is negative. Furthermore, it is straightforward to observe that all terms in (15) and (16) are increasing (in absolute value) in $\rho$. Thus, an increase in $\rho$ will always reinforce the negative effect of opacity on the volatility of inflation and the output gap while it is unclear how the marginal effect of opacity on both variances vary with the initial degree of opacity. Some simulation exercises (see Table 1, Section 5), using benchmark parameter values $\beta=0.99, \lambda=0.5$ and $\delta=0.08$, show that the effects of opacity on the volatility of inflation (the output gap) are always negative (positive) and exponentially amplified with the degree of persistence, while higher initial degrees of opacity moderately reduce the marginal effects of opacity. If we use the following measure:

$$
W^{S}=-\frac{1}{2} \mathrm{E}_{t} \sum_{i=0}^{\infty} \beta^{i}\left[\lambda x_{t+i}^{2}+\pi_{t+i}^{2}\right]
$$

our numerical examples show that, for $\lambda=0.5$ and $\rho<0.433$, an increase in opacity would actually decrease social welfare but will improve more and more strongly social welfare when $\rho$ approaches unity.

Our results are significantly different from these obtained in the Barro-Gordon framework. Eijffinger et al. (2000) find that the mean and variance of inflation increase with imperfect transparency and monetary uncertainty may have a positive effect on output stabilization, and therefore also on society's welfare. Their results are contested by Beetsma and Jensen (2003), who have shown that expected inflation and macroeconomic volatility are sensitive to the arbitrary specification of uncertainty about one or the other parameter attached to the central bank's objectives. Following Beetsma and Jensen, Geraats (2002) and Demertzis and Hughes Hallett (2007) have found similar results by normalizing the inflation 
elasticity of the supply curve at one and choosing the preference weights so as to have their sum equal to one in order to eliminate the effects of arbitrary specification of imperfect transparency. Nevertheless, introducing distortionary taxes in the Barro-Gordon framework and fiscal and monetary interactions allows imperfect transparency to eventually have some welfare-improving effects (Hughes Hallett and Viegi, 2003; Ciccarone et al., 2007; Hefeker and Zimmer, 2011b).

\subsection{The dynamic effects of central bank transparency}

In the above, we have determined the equilibrium solution of $\mathrm{E}_{t} \pi_{t+1}$. To examine the effect of central bank opacity on the dynamic adjustments, we now consider the complementary solution of $\mathrm{E}_{t} \pi_{t+1}$, i.e. its deviations from the equilibrium. According to (5), we have

$$
\pi_{t}=\beta \Theta\left(\mathrm{E}_{t} \pi_{t+1}+\frac{1}{\beta} e_{t}\right)
$$

Taking the mathematical expectations of the equivalent of (18) for all future periods and iteratively substituting future inflation expectations leads to the general solution of $\mathrm{E}_{t} \pi_{t+1}$ :

$$
\mathrm{E}_{t} \pi_{t+1}=\left[\beta \mathrm{E}_{t}(\Theta)\right]^{n} \mathrm{E}_{t} \pi_{t+n+1}+\mathrm{E}_{t}(\Theta) \sum_{i=1}^{n}\left[\beta \mathrm{E}_{t}(\Theta)\right]^{i-1} \mathrm{E}_{t} e_{t+i}
$$

We observe that it is the value of $\beta \mathrm{E}_{t}(\Theta)$ which determines how quickly the expected inflation converges to the steady state equilibrium after a persistent current inflation shock or a future inflation shock occurs. Deriving $\mathrm{E}_{t}(\Theta)$ with respect to $\sigma_{\varepsilon}^{2}$ gives $\frac{\partial \mathrm{E}_{t}(\Theta)}{\partial \sigma_{\varepsilon}^{2}}=-\frac{\delta^{2}(1+\lambda)\left(1-\delta^{2}\right)}{\left(\lambda+\delta^{2}\right)^{3}}<0, \forall \delta<1$. This implies that the composite coefficient $\beta \mathrm{E}_{t}(\Theta)$ in (19), which is lower than unity, becomes further smaller. 
Proposition 5. Under optimal discretion, a higher degree of central bank opacity will increase the speed of convergence of inflation expectations to their equilibrium levels, for $\delta<1$

To exclude the bubbles in the solution of expected future inflation given by (19), one must impose the transversality condition, i.e. $\lim _{n \rightarrow+\infty}\left[\beta \mathrm{E}_{t}(\Theta)\right]^{n} \mathrm{E}_{t} \pi_{t+n+1}=0$. If we only consider stochastic serially correlated shocks, when $n \rightarrow+\infty$ in equation (19), we obtain the solution of $\mathrm{E}_{t} \pi_{t+1}$ given in (7). Consequently, the effect of opacity is only reflected by a smaller static error in inflation expectations.

However, when a persistent inflation shock hits the economy or a future event at time $T$ is immediately known (i.e., a preannounced future policy or a known future shock), the expected inflation rate will begin to evolve from time $t$ until the steady state is reached. Consequently, the dynamic effects of such a current shock or future event will be affected by imperfect central bank transparency through the term $E_{t}(\Theta)$. An increase in opacity reduces the value of $\beta \mathrm{E}_{t}(\Theta)$ for $\delta<1$ and hence accelerates, during the transition period until the equilibrium is reached, the convergence speed of the expected future inflation rate to its long term trend. The latter is equal to zero given that the inflation target of the central bank is zero.

An alternative way to consider the convergence issue is to examine the expected eigenvalue of the inflation dynamic equation (5), which is given by $\mathrm{E}_{t}(\Lambda)=\frac{1}{\beta}+\frac{\delta^{2}}{\beta} \mathrm{E}_{t}(\Phi)>1$, where $\mathrm{E}_{t}(\Phi) \equiv \mathrm{E}_{t}\left(\frac{1+\varepsilon}{\lambda-\varepsilon}\right)$, with its second-order Taylor approximation as $\mathrm{E}_{t}(\Phi) \cong \frac{1}{\lambda}+\frac{1+\lambda}{\lambda^{3}} \sigma_{\varepsilon}^{2}$.

Since the inflation is a forward-looking variable, for the system to be stable, its eigenvalue $\Lambda$ and hence its expected eigenvalue $\mathrm{E}_{t}(\Lambda)$ must be outside the unit circle. Deriving the expected eigenvalue $\mathrm{E}_{t}(\Lambda)$ with respect to $\sigma_{\varepsilon}^{2}$ gives

$$
\frac{\partial \mathrm{E}_{t}(\Lambda)}{\partial \sigma_{\varepsilon}^{2}} \cong \frac{\delta^{2}(1+\lambda)}{\beta \lambda^{3}}>0 .
$$


According to (20), $\mathrm{E}_{t}(\Lambda)$ is greater when the degree of opacity increases. Therefore, imperfect transparency ensures a more rapid convergence of inflation expectations to their equilibrium level whenever the economy is perturbed by a current shock or foreseeable future exogenous or policy shocks, while not affecting the stability properties of the inflation dynamics.

In effect, according to equations (4) and (18), for a given shock affecting central bank preferences $(\varepsilon)$, a faster dynamic adjustment of inflation expectations also implies that inflation and the output gap adjust more quickly. Departing from the benchmark case where the central bank is perfectly transparent, an increase in opacity will allow, on average, the central bank to reduce the reaction of inflation and the output gap to inflation shocks. A smaller response of optimal monetary policy makes the system converge more rapidly to the equilibrium. A quicker dynamic adjustment implies that the economy will shortly stay in each state of disequilibrium, implying less negative consequences for social welfare.

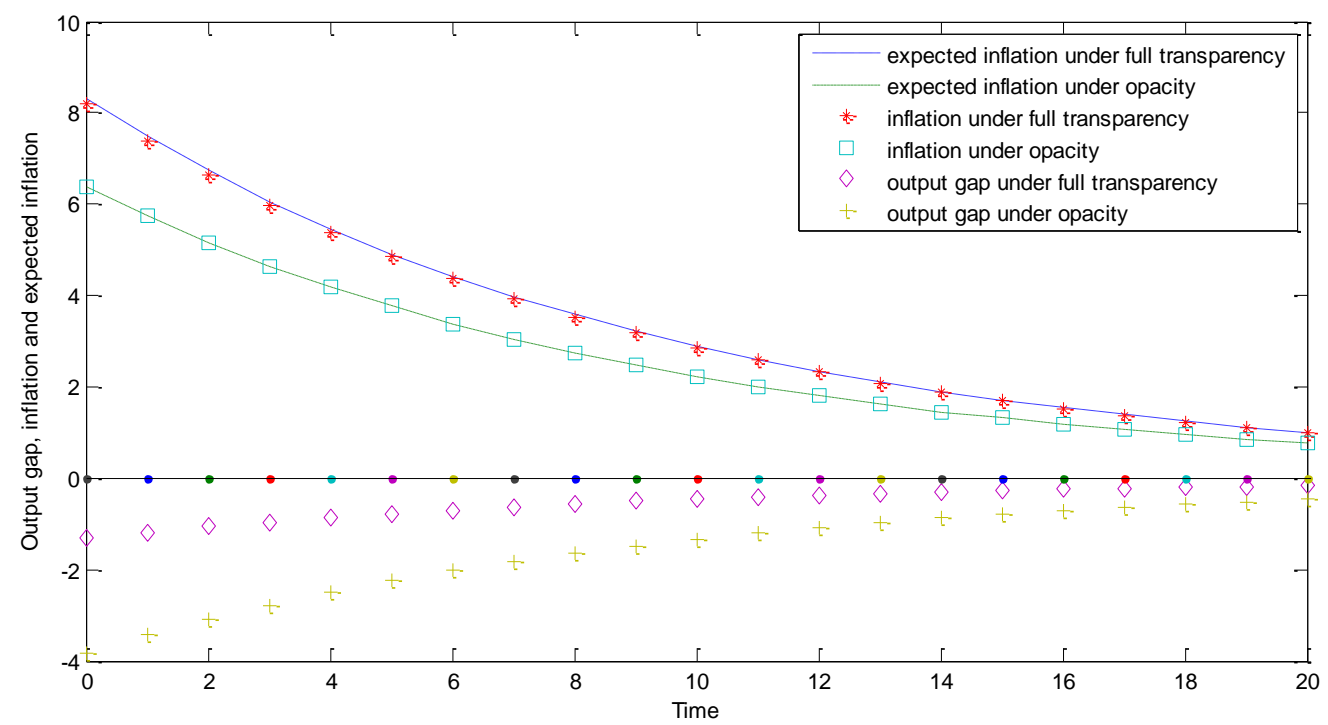

Figure 2: Comparison of average impulse responses of inflation expectations, inflation and the output gap to a one-percent inflation shock under optimal discretion with $\beta=0.99, \lambda=0.5, \delta=0.08, \lambda=0.5$, and $\rho=0.90$.

However, when analyzing the effects of opacity on inflation and the output gap, one must also take account of the direct effects of the central bank's preference shocks by computing 
the average responses of inflation and the output gap. As shown in equations (13) and (14) and in Propositions 2, 3a and 3b, an increase in opacity will accelerate the dynamic adjustment of inflation and the output gap through the inflation expectations channel but have opposite effects through the policy rule channel. Under the assumption that $\delta<1$, shocks on central bank preferences will accelerate on average the adjustment of inflation but decrease that of the output gap during the transition to the steady state equilibrium (Figure 2). Nevertheless, the possible dynamic costs of preference shocks for the society through the policy rule channel could be dominated by the dynamic positive effect of opacity on social welfare through the inflation expectations channel. It is more likely if the weight assigned to the output-gap stabilization relative to the inflation stabilization is low.

\section{Optimal monetary policy under pre-commitment in a timeless perspective}

Optimal monetary policy can also be characterized by commitment. Under optimal commitment, the central bank chooses at time $t$ both current and expected future values of inflation and the output gap and it takes advantage of the forward-looking nature of inflation expectations through the introduction of policy inertia. Optimal pre-commitment generally leads to higher social welfare than under discretion since the latter, but, while eliminating the inflation bias, it could generate a stabilization bias. To successfully affect inflation expectations, the commitment to a future path of policy needs to be credible. Thus, central bank transparency would appear to be a prerequisite for such a strategy. However, we are not certain that imperfect transparency adds a supplementary and welfare-reducing constraint to the central bank's optimization problem under commitment in the New Keynesian framework which emphasizes the forward-looking behavior of the price setters. 
We consider that the central bank can credibly commit to future policies. More specifically, we will consider that the central bank adopts a timeless perspective in optimal pre-commitment monetary policy rule to eliminate the dynamic inconsistency.

In the following, we first present equilibrium solutions. We then examine the effects of imperfect transparency on the level and variance of macroeconomic variables before investigating its effect on the dynamic adjustment.

\subsection{Equilibrium}

Under commitment monetary policy, private sector's inflation expectations are not taken as given but are instead considered as variables that can be influenced by monetary authorities to achieve policy objectives. Optimal monetary policy under commitment is obtained by minimizing (3) subject to (1) for all periods $t, t+1, t+2, \ldots, t+n$. The first-order conditions of this minimization problem can be rearranged to yield:

$$
\begin{aligned}
& \pi_{t}=-\frac{\lambda-\varepsilon}{\delta(1+\varepsilon)} x_{t}, \\
& \pi_{t+s}=-\frac{\lambda-\varepsilon}{\delta(1+\varepsilon)}\left(x_{t+s}-x_{t+s-1}\right), \quad \text { for } s=1,2,3 \ldots
\end{aligned}
$$

The time inconsistency of the commitment solution becomes evident when comparing (21) and (22), since (21) places a requirement that is specific to the current period and is different from the corresponding requirement (22) for later periods.

The timeless perspective resolution (Woodford, 1999) to the problem of the time inconsistency of optimal policy consists for the policymaker to respect the optimality conditions derived above, except for the current period when the optimization takes place. This amounts to using (22) also for the current period and neglecting (21), yielding the commitment optimality condition: ${ }^{4}$

\footnotetext{
${ }^{4}$ See also Clarida et al. (1999), and McCallum and Nelson (2004).
} 


$$
\pi_{t}=-\frac{\lambda-\varepsilon}{\delta(1+\varepsilon)}\left(x_{t}-x_{t-1}\right)
$$

The dynamic system in $x_{t}$ and $\pi_{t}$ defined by (1) and (23) has a unique non-explosive rational expectations solution. Using the method of undetermined coefficients to obtain the “minimal state variable" (MSV) solution (McCallum, 1983), we express it as a linear function of the state variables $x_{t-1}$ and $e_{t}$ as follows:

$$
\begin{aligned}
& \pi_{t}=b_{\pi} x_{t-1}+c_{\pi} e_{t}, \\
& x_{t}=b_{x} x_{t-1}+c_{x} e_{t},
\end{aligned}
$$

Following McCallum and Nelson (2004), and taking account of the uncertainty about central bank preferences, we find that the expected value of $b_{x}$, i.e. $\mathrm{E}_{t}\left(b_{x}\right)$, must satisfy

$$
\beta\left[\mathrm{E}_{t}\left(b_{x}\right)\right]^{2}-\gamma \mathrm{E}_{t}\left(b_{x}\right)+1=0,
$$

where $\gamma=1+\beta+\delta^{2} \mathrm{E}_{t}(\Phi)$. Equation (26) has two solutions. The one of interest, which delivers the stationary rational expectations equilibrium for all values of structural parameters and corresponds to the policy optimum, is in the unity circle and is given by

$$
\mathrm{E}_{t}\left(\bar{b}_{x}\right)=\frac{\gamma-\sqrt{\gamma^{2}-4 \beta}}{2 \beta}
$$

Using (27) into conditions relating coefficients $b_{\pi}, c_{\pi}, b_{x}$ and $c_{x}$ to obtain their solution and inserting it into (24) and (25) lead to

$$
\begin{aligned}
& \left.\mathrm{E}_{t} \pi_{t+1}\right|_{\text {commitment }}=\frac{1-\mathrm{E}_{t}\left(\bar{b}_{x}\right)}{\delta \mathrm{E}_{t}(\Phi)} \mathrm{E}_{t}\left(\bar{b}_{x}\right) x_{t-1}+\frac{\rho-1+\mathrm{E}_{t}\left(\bar{b}_{x}\right)}{1+\beta(1-\rho)+\delta^{2} \mathrm{E}_{t}(\Phi)-\beta \mathrm{E}_{t}\left(\bar{b}_{x}\right)} e_{t}, \\
& \left.\pi_{t}\right|_{\text {commitment }}=\Theta\left\{\left[\delta+\frac{\beta\left[1-\mathrm{E}_{t}\left(\bar{b}_{x}\right)\right]}{\delta \mathrm{E}_{t}(\Phi)} \mathrm{E}_{t}\left(\bar{b}_{x}\right)\right] x_{t-1}+\frac{1+\delta^{2} \mathrm{E}_{t}(\Phi)}{1+\beta(1-\rho)+\delta^{2} \mathrm{E}_{t}(\Phi)-\beta \mathrm{E}_{t}\left(\bar{b}_{x}\right)} e_{t}\right\}, \\
& \left.x_{t}\right|_{\text {commitment }}=x_{t-1}-\delta \Omega\left\{\left[\delta+\frac{\beta\left[1-\mathrm{E}_{t}\left(\bar{b}_{x}\right)\right]}{\delta \mathrm{E}_{t}(\Phi)} \mathrm{E}_{t}\left(\bar{b}_{x}\right)\right] x_{t-1}+\frac{1+\delta^{2} \mathrm{E}_{t}(\Phi)}{1+\beta(1-\rho)+\delta^{2} \mathrm{E}_{t}(\Phi)-\beta \mathrm{E}_{t}\left(\bar{b}_{x}\right)} e_{t}\right\} .
\end{aligned}
$$




\subsection{Effects of opacity on macroeconomic performance under pre-commitment}

Under perfect transparency, discretion leads to a stabilization bias and lower social welfare (in general) than under optimal pre-commitment in a timeless perspective (McCallum and Nelson, 2004). In effect, under commitment, the central bank chooses, at time $t$, both current and expected future values of inflation and the output gap. Before comparing the effects of imperfect transparency across these two monetary policy regimes, we first explore its effects on the level and variance of inflation and the output gap under pre-commitment.

Deriving the level of inflation and the output gap given by (29)-(30) with respect to $\sigma_{\varepsilon}^{2}$ leads to the following propositions.

Proposition 6a. Under optimal pre-commitment in a timeless perspective, an increase in central bank opacity will generally reduce the dependence of inflation on the past output gap and increase that of the output gap.

A sufficient condition $\delta^{2} \mathrm{E}_{t}(\Phi)>\frac{1-\beta}{2}$ can be imposed to ensure the effects reported in Proposition $6 \mathrm{a}$ to be verified with certainty. For $\beta$ near to unity and small $\delta$, this condition could be satisfied if $\lambda$ is relatively small. However, even if this condition is not verified, it is very probable that Proposition 6a is still valid, since other factors clearly play in the sense of attenuating the dependence of inflation on the past output gap.

Numerical exercises show that for $\beta=0.99$, the effect of opacity on the dependence of inflation (the output gap) on the past output gap will be reinforced (weakened) only if $\delta^{2} \mathrm{E}_{t}(\Phi)$ is smaller than a threshold situated between 0.00009 to 0.00010 . When $\delta$ takes a conventional value as adopted in the New-Keynesian models, e.g. $\delta=0.08$, the central bank must attribute a very large value to its preference parameter $\lambda$. This is unlikely because the inflation-targeting central bank generally emphasizes on inflation stabilization. 
Proposition 6b. Under optimal pre-commitment in a timeless perspective, an increase in the central bank opacity will reduce the sensitivity of current inflation and that of the current output gap to the inflation shock if $\frac{1}{2}-\rho-\frac{4-\gamma}{2 \sqrt{\gamma^{2}-4 \beta}}<0$. These effects are reinforced by an increase in the degree of persistence of inflation shocks.

When the inflation shock is not persistent, i.e., $\rho=0$, the condition in Proposition $6 \mathrm{~b}$ becomes $\frac{1}{2}-\frac{4-\gamma}{2 \sqrt{\gamma^{2}-4 \beta}}<0$. This condition could be expressed as $\delta^{2} \mathrm{E}_{t}(\Phi)<1-\frac{\beta}{2}$. The latter will be generally verified given that $\delta$ is small and the central banker does not focus too strongly on the inflation target, implying that $\lambda$ is large. Furthermore, a lower initial degree of opacity will make the condition easier to be satisfied.

The results reported in Propositions $6 \mathrm{a}$ and $6 \mathrm{~b}$ are explained by the inflation expectations channel. In effect, a decrease in transparency will reduce the reaction of expected inflation to the past output gap and inflation shocks. Lower inflation expectations will simultaneously allow reducing the responses of inflation and the output gap to inflation shocks. On the other hand, opacity has divergent effects on the dependence of inflation and the output gap on the past output gap because their dependence on the latter is inversely related according to the monetary policy rule under pre-commitment, i.e. equation (23).

We find that an increase in opacity will reduce the average reaction of inflation to inflation shocks if $\delta^{2} \mathrm{E}_{t}(\Phi)<\frac{1-\beta}{2}$ which is a sufficient condition to ensure that the effect through the inflation expectations channel is also negative, as that through the policy rule channel. The effects of imperfect transparency on the reaction of the output gap through the two channels are in opposite sense. It seems impossible to obtain some clear-cut conditions in order to evaluate their relative importance. Numerical simulations for $\beta=0.99, \lambda=0.5$, $\delta=0.08$ and $\sigma_{\varepsilon}^{2}$ show that the effect of opacity on both variables through the policy rule 
channel is generally larger than that through the inflation expectations channel. These marginal effects of opacity are amplified with a higher degree of persistence of inflation shocks but weakened by an increase in the initial degree of opacity. Thus, for plausible parameter values, an increase in opacity will amplify the average reactions of the output gap to inflation shocks and more so when the degree of persistence of inflation shocks is higher.

Proposition 6c. Under optimal pre-commitment in a timeless perspective, an increase in the central bank opacity will generally reduce (increase) the average reaction of current inflation (the current output gap) to inflation shocks. These marginal effects are reinforced (weakened) by an increase in the degree of persistence of inflation shocks (the initial degree of opacity).

Using (29) and (30) to compute the variances of inflation and the output gap respectively and then twice deriving them with respect to $x_{t-1}^{2}$ and $\sigma_{\varepsilon}^{2}$ yield:

$$
\begin{aligned}
& \left.\frac{\partial^{2} \operatorname{var}\left(\pi_{t}\right)}{\partial\left(x_{t-1}^{2}\right) \partial \sigma_{\varepsilon}^{2}}\right|_{\text {commitment }}=\delta^{4} \mathrm{~A}_{x}+\left\{\mathrm{E}_{t}\left(\Theta^{2}\right)-\left[\mathrm{E}_{t}(\Theta)\right]^{2}\right\} \mathrm{B}_{x}, \\
& \left.\frac{\partial^{2} \operatorname{var}\left(x_{t}\right)}{\partial\left(x_{t-1}^{2}\right) \partial \sigma_{\varepsilon}^{2}}\right|_{\text {commitment }}=\mathrm{A}_{x}+\left\{\mathrm{E}_{t}\left(\Omega^{2}\right)-\left[\mathrm{E}_{t}(\Omega)\right]^{2}\right\} \mathrm{B}_{x},
\end{aligned}
$$

where

$$
\begin{aligned}
& \mathrm{A}_{x}=\left[\frac{(1+\lambda)^{2}}{\left(\lambda+\delta^{2}\right)^{4}}-\frac{2(1+\lambda)^{2}\left(1-\delta^{2}\right)^{2}}{\left(\lambda+\delta^{2}\right)^{6}} \sigma_{\varepsilon}^{2}\right]\left\{\delta+\frac{\beta\left[1-\mathrm{E}_{t}\left(\bar{b}_{x}\right)\right] \mathrm{E}_{t}\left(\bar{b}_{x}\right)}{\delta \mathrm{E}_{t}(\Phi)}\right\}^{2}, \\
& \mathrm{~B}_{x}=\frac{2 \beta(1+\lambda) \mathrm{E}_{t}\left(\bar{b}_{x}\right)}{\delta \lambda^{3}\left[\mathrm{E}_{t}(\Phi)\right]^{2}}\left[\delta+\frac{\beta\left[1-\mathrm{E}_{t}\left(\bar{b}_{x}\right)\right] \mathrm{E}_{t}\left(\bar{b}_{x}\right)}{\delta \mathrm{E}_{t}(\Phi)}\right]\left[1-\mathrm{E}_{t}\left(\bar{b}_{x}\right)+\frac{\delta^{2}\left[1-2 \mathrm{E}_{t}\left(\bar{b}_{x}\right)\right]\left[\mathrm{E}_{t}(\Phi)\right]}{\sqrt{\gamma^{2}-4 \beta}}\right] .
\end{aligned}
$$

Our numerical exercises show that the dependence of the volatility of inflation and the output gap on the past output gap is weakly affected by an increase in the degree of opacity 
whatever is the initial degree of opacity. Furthermore, these effects are independent of the degree of persistence of inflation shocks.

Deriving the variances of inflation and the output gap with respect to $\sigma_{e}^{2}$ and $\sigma_{\varepsilon}^{2}$ yields:

$$
\begin{aligned}
& \left.\frac{\partial^{2} \operatorname{var}\left(\pi_{t}\right)}{\partial \sigma_{e}^{2} \partial \sigma_{\varepsilon}^{2}}\right|_{\text {commitment }}=\left(\delta^{2}+3 \lambda \delta^{2}-2 \lambda\right) \mathrm{A}_{e}+\beta \mathrm{E}_{t}\left(\Theta^{2}\right) \mathrm{B}_{e}, \\
& \left.\frac{\partial^{2} \operatorname{var}\left(x_{t}\right)}{\partial \sigma_{e}^{2} \partial \sigma_{\varepsilon}^{2}}\right|_{\text {commitment }}=\left(\lambda+3-2 \delta^{2}\right) \mathrm{A}_{e}+\delta^{2} \mathrm{E}_{t}\left(\Omega^{2}\right) \mathrm{B}_{e},
\end{aligned}
$$

where

$$
\begin{aligned}
& \mathrm{A}_{e}=\frac{\delta^{2}(1+\lambda)}{\left(\lambda+\delta^{2}\right)^{4}}\left[\frac{1+\delta^{2} \mathrm{E}_{t}(\Phi)}{1+\beta(1-\rho)+\delta^{2}(\Phi)-\beta \mathrm{E}_{t}\left(\bar{b}_{x}\right)}\right]^{2}, \\
& \mathrm{~B}_{e}=\frac{2 \beta \delta^{2}(1+\lambda)\left[1+\delta^{2}(\Phi)\right]}{\lambda^{3}\left[1+\beta(1-\rho)+\delta^{2}(\Phi)-\beta \mathrm{E}_{t}\left(\bar{b}_{x}\right)\right]^{3}}\left[\frac{1}{2}-\rho-\frac{4-\gamma}{2 \sqrt{\gamma^{2}-4 \beta}}\right]
\end{aligned}
$$

In (33) and (34), the first term represents the direct effect of opacity due to the impact of the central bank's preference shocks on the trade-off between inflation and the output gap (i.e., the slope of monetary policy rule) and hence on the level of inflation and the output gap. Given that the value attributed to $\delta$ is quite small in the New Keynesian models, this implies that if the central bank assigns a sufficiently high weight to the output-gap stabilization, i.e. $\lambda>\frac{\delta^{2}}{2-3 \delta^{2}}$, the direct effect of opacity on the volatility of inflation will be negative. For conventional value of $\delta$, the expression $\left(\lambda+3-2 \delta^{2}\right)$ is clearly positive. As a result, the direct effect of opacity on the volatility of the output gap will be positive. These effects will be reinforced by an increase in the degree of persistence of inflation shocks.

The second term in (33) and (34) represents the effects of imperfect transparency through the inflation expectation channel where an increase in the degree of persistence of inflation shock will reinforce the negative effect of opacity on the expected inflation rate, reducing thus 
the volatility of inflation and the output gap simultaneously. In the expression of $\mathrm{B}_{e}$, it is easy to see that higher values of $\rho$ will increase the possibility of $\mathrm{B}_{e}$ being negative or make it increasingly negative if it is already the case. In effect, we have $\mathrm{B}_{e}<0$ (or equivalently $\left.\frac{1}{2}-\rho-\frac{4-\gamma}{2 \sqrt{\gamma^{2}-4 \beta}}<0\right)$ if $\delta^{2} \mathrm{E}_{t}(\Phi)<1-\frac{\beta}{2}$, where $\mathrm{E}_{t}(\Phi)$ is negatively related to $\lambda$. A smaller $\delta$ implies that an increase in the output gap has a less important effect on inflation. A higher $\lambda$ will positively affect the costs of an increase in the output gap, strengthening the incentive for the central bank to augment inflation while less decreasing the output gap in the event of a positive inflation shock. Therefore, these two parameters will affect inflation expectations inversely, reflecting such trade-offs of the central bank in the future.

Knowing that $\frac{-(4-\gamma)}{2 \sqrt{\gamma^{2}-4 \beta}}$ is increasing in $\gamma$ and capped by $\frac{1}{2}$ as $\gamma \rightarrow+\infty$, i.e. $\lambda \rightarrow 0$, one might conjecture that even though the second term in $(31)$, i.e. $\left.-\left[\mathrm{E}_{t}(\Theta)\right]^{2}\right\} \mathrm{B}_{x}>0$, has a positive contribution to the total volatility of inflation, it might not dominate the negative direct effect of opacity on the volatility of inflation while a positive indirect effect represented by the second term in (32), i.e. $\left.-\left[\mathrm{E}_{t}(\Omega)\right]^{2}\right\} \mathrm{B}_{x}>0$, will reinforce the positive direct effect of opacity on the volatility of the output gap.

Some simulation exercises are conducted for $\beta=0.99, \delta=0.08, \lambda=0.50$ and $\sigma_{\varepsilon}^{2}=0.45$, showing that the global effect of opacity on the sensitivity of the volatility of inflation (the output gap ) to the volatility of inflation shock is negative (positive). The sensitivity of the volatility of inflation (the output gap) will change from -0.4163 to -11.7915 (from 0.3489 to 1.3138 ) when $\rho$ passes from 0.1 to 0.99 . A weak initial degree of opacity will significantly reinforce the above effects only if $\rho$ is relatively high (see Table 1 , Section 5). For different initial degrees of opacity, the negative effects of opacity on the volatility of 
inflation largely dominate its positive effects on the volatility of the output gap and the difference increases exponentially with the degree of persistence of inflation shocks.

Proposition 7. Under optimal pre-commitment in a timeless perspective, an increase in opacity will generally decrease the reaction of the volatility of inflation to the volatility of inflation shocks more significantly than increase that of the volatility of the output gap if the degree of persistence of inflation shocks is sufficiently high. In general, it will improve social welfare if the weight assigned by the society to output-gap stabilization is relatively low.

Here, similar to the case of optimal discretion, an increase in opacity decreases more the costs of achieving a higher output-gap when the trade-off between inflation and the output gap is high (i.e., when the inflation shock is more persistent) than when the trade-off is low (i.e., when the inflation shock is less persistent). It has thus large smoothing effects on inflation without significantly amplifying the fall in the output gap, once the effects of idiosyncratic preference shocks are also taken into account.

\subsection{Effects of opacity on macroeconomic dynamics under pre-commitment}

When studying the economic dynamics under discretion, we find that the dynamic system of the economy is affected by opacity through the inflation expectations channel while future inflation expectations are affected by the effects of central bank's preference shocks which modify the policy rule and hence the optimal trade-off between inflation and the output gap in all future periods. Under optimal pre-commitment, these dynamic effects are present but are affected by the pre-commitment of the monetary authority in a timeless perspective, which implies that the policy rule also depends on the past output gap.

Using equations (1) and (23), we write the dynamic system of expected future inflation and output gap in a matrix form as follows: 


$$
\left[\begin{array}{c}
\mathrm{E}_{t} x_{t+1} \\
\mathrm{E}_{t} \pi_{t+1}
\end{array}\right]=\left[\begin{array}{cc}
1+\delta^{2} \mathrm{E}_{t}(\Phi) / \beta & -\delta \mathrm{E}_{t}(\Phi) / \beta \\
-\delta / \beta & 1 / \beta
\end{array}\right]\left[\begin{array}{c}
x_{t} \\
\pi_{t}
\end{array}\right]+\left[\begin{array}{c}
\delta \mathrm{E}_{t}(\Phi) / \beta \\
-1
\end{array}\right] e_{t}
$$

The eigenvalues of the stability matrix are given by

$$
J_{1}=\frac{\gamma-\sqrt{\gamma^{2}-4 \beta}}{2 \beta}<1, J_{2}=\frac{\gamma+\sqrt{\gamma^{2}-4 \beta}}{2 \beta}>1 \text {. }
$$

Following Blanchard and Kahn (1980) and King and Watson (1998), we associate the unstable eigenvalue $J_{2}$ which is outside the unit circle with the forward-looking variable, i.e., $\mathrm{E}_{t} \pi_{t+1}$. Its value captures the speed of convergence of inflation expectations. A greater $J_{2}$ implies that $\mathrm{E}_{t} \pi_{t+1}$ converges more quickly to its equilibrium value. Using the definition of $\gamma$, we can show that

$$
\frac{\partial \mathrm{E}_{t}\left(J_{2}\right)}{\partial \sigma_{\varepsilon}^{2}}=\frac{\delta^{2}(1+\lambda)}{\beta \lambda^{3}}\left(\frac{\gamma+\sqrt{\gamma^{2}-4 \beta}}{2 \sqrt{\gamma^{2}-4 \beta}}\right)>0
$$

The partial derivative reported in (36) implies that the convergence speed of inflation expectations is clearly accelerated by a decrease in central bank transparency. Through the inflation expectations channel, opacity will increase the speed of convergence of inflation and the output gap for a given preference shock. As in the case of optimal discretion, when a large number of preference shocks occur during the transition to the equilibrium, to measure the dynamic effects on social welfare, one must compute the average reactions of inflation and the output gap to inflation shocks. Our previous analysis and simulation exercises imply that if $\delta<1$, preference shocks will, on average, accelerate the adjustment of inflation but decrease in general that of the output gap during the dynamic adjustment (Figure 3).

Proposition 8. Under optimal pre-commitment in a timeless perspective, an increase in opacity will accelerate the convergence of inflation expectations and current inflation to their equilibrium levels but will decrease the speed of convergence of the output gap. 
On balance, the dynamic costs for the society, in terms of higher volatility of the output gap due to the effect of preference shocks via the policy rule channel, could nevertheless be dominated by the dynamic benefits of opacity on social welfare through the inflation expectations channel (lower volatilities of inflation and the output gap) as well as through the policy rule channel (lower volatility of inflation) if the relative weight assigned to output-gap stabilization is low.

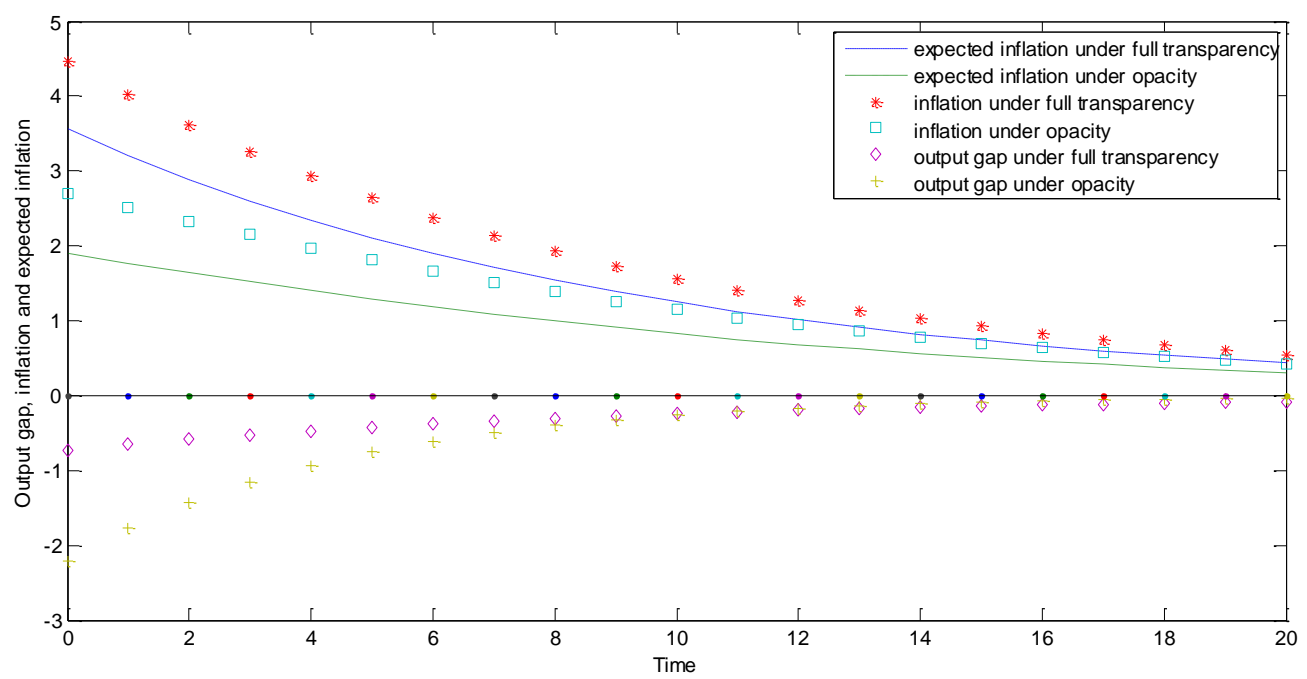

Figure 3: Comparison of average impulse responses of inflation expectations, inflation and the output gap to a one-percent inflation shock under optimal pre-commitment with $\beta=0.99, \lambda=0.5, \delta=0.08, \lambda=0.5$, and $\rho=0.90$.

\section{Discretion versus pre-commitment: A comparison of the effects of opacity}

Commitment policy induces some inertia in the conduct of monetary policy that leads to the dependence of endogenous variables on the past level of the output gap while giving the central bank the possibility of reacting to unanticipated inflation shocks as under discretion. This implies that the dynamic and static effects of decreased transparency could have significant differences under these two policy regimes.

\subsection{Effects of opacity on macroeconomic volatility}


Comparing the volatilities of inflation and the output gap under these two policy regimes, we find that they reacts less to the volatility of inflation shocks under pre-commitment than under discretion if

$$
\rho>\frac{1-\mathrm{E}_{t}\left(\bar{b}_{x}\right)}{1+\left[1+\delta^{2} \mathrm{E}_{t}(\Phi)\right] \mathrm{E}_{t}(\Theta)} .
$$

In effect, as inflation shocks become more persistent, the discretion will perform less well in stabilizing inflation and the output gap since it becomes more difficult to surprise the private sector. However, the increase in inflation expectations due to higher degree of persistence of inflation shocks will augment the role of opacity. Under pre-commitment, inflation expectations are better anchored by the commitment to the inflation target. Therefore, less transparency is more likely to have a large negative effect on inflation expectations under discretion than under pre-commitment when the degree of persistence of inflation shocks is high enough. For the same reason, the volatility of the output gap under discretion could be more amplified by an increase in the degree of persistence of inflation shocks than under pre-commitment. Thus, on balance, macroeconomic performance could be more improved by imperfect transparency under optimal pre-commitment than under optimal discretion.

The effects of opacity on the macroeconomic volatility crucially depend on the degree of persistence of inflation shocks but less significantly on the initial degree of opacity. Using $\beta=0.99, \lambda=0.5$ and $\delta=0.08$, we vary the initial degree of opacity and the degree of persistence of inflation shocks to see their joint influences on the volatility of inflation and the output gap and compare the impact of imperfect transparency on macroeconomic volatility under the two policy regimes.

The results are reported in Table 1. They allow us to make several observations. First, the effects of an increase in opacity are not strongly affected by the change of the initial degree of 
opacity when the degree of persistence of inflation shocks is low. In contrast, they are very sensitive to the degree of persistence of inflation shocks for a given initial degree of opacity.

Table 1: The effect of an increase in opacity on macroeconomic volatility.

\begin{tabular}{|c|r|r|r|r|r|}
\hline$\sigma_{\varepsilon}^{2}=0.05$ & $\rho=0.1$ & $\rho=0.3$ & $\rho=0.50$ & $\rho=0.70$ & $\rho=0.90$ \\
\hline$\partial^{2} \operatorname{var}\left(\pi_{t}\right) /\left.\partial \sigma_{e}^{2} \partial \sigma_{\varepsilon}^{2}\right|_{c o m}$ & -0.7499 & -1.3691 & -2.9689 & -8.7168 & -50.4900 \\
\hline$\partial^{2} \operatorname{var}\left(\pi_{t}\right) /\left.\partial \sigma_{e}^{2} \partial \sigma_{\varepsilon}^{2}\right|_{d i s}$ & -0.1955 & -0.4057 & -1.0667 & -4.4726 & -76.6026 \\
\hline$\partial^{2} \operatorname{var}\left(x_{t}\right) /\left.\partial \sigma_{e}^{2} \partial \sigma_{\varepsilon}^{2}\right|_{c o m}$ & 0.4609 & 0.6937 & 1.1596 & 2.3116 & 6.5345 \\
\hline$\partial^{2} \operatorname{var}\left(x_{t}\right) /\left.\partial \sigma_{e}^{2} \partial \sigma_{\varepsilon}^{2}\right|_{d i s}$ & 0.6246 & 1.0148 & 1.9285 & 4.9927 & 32.5939 \\
\hline$\sigma_{\varepsilon}^{2}=0.25$ & & & & & \\
\hline$\partial^{2} \operatorname{var}\left(\pi_{t}\right) /\left.\partial \sigma_{e}^{2} \partial \sigma_{\varepsilon}^{2}\right|_{c o m}$ & -0.5210 & -0.9074 & -1.8344 & -4.7679 & -20.7467 \\
\hline$\partial^{2} \operatorname{var}\left(\pi_{t}\right) /\left.\partial \sigma_{e}^{2} \partial \sigma_{\varepsilon}^{2}\right|_{d i s}$ & -0.1942 & -0.3966 & -1.0152 & -4.0282 & -55.8905 \\
\hline$\partial^{2} \operatorname{var}\left(x_{t}\right) /\left.\partial \sigma_{e}^{2} \partial \sigma_{\varepsilon}^{2}\right|_{c o m}$ & 0.3917 & 0.5635 & 0.8756 & 1.5203 & 2.9690 \\
\hline$\partial^{2} \operatorname{var}\left(x_{t}\right) /\left.\partial \sigma_{e}^{2} \partial \sigma_{\varepsilon}^{2}\right|_{d i s}$ & 0.6198 & 0.9852 & 1.8016 & 4.2806 & 19.4597 \\
\hline$\sigma_{\varepsilon}^{2}=0.45$ & & & & & \\
\hline$\partial^{2} \operatorname{var}\left(\pi_{t}\right) /\left.\partial \sigma_{e}^{2} \partial \sigma_{\varepsilon}^{2}\right|_{\text {com }}$ & -0.4163 & -0.7010 & -1.3489 & -3.2286 & -11.7915 \\
\hline$\partial^{2} \operatorname{var}\left(\pi_{t}\right) /\left.\partial \sigma_{e}^{2} \partial \sigma_{\varepsilon}^{2}\right|_{d i s}$ & -0.1930 & -0.3877 & -0.9667 & -3.6381 & -41.9151 \\
\hline$\partial^{2} \operatorname{var}\left(x_{t}\right) /\left.\partial \sigma_{e}^{2} \partial \sigma_{\varepsilon}^{2}\right|_{\text {com }}$ & 0.3489 & 0.4860 & 0.7174 & 1.1338 & 1.7381 \\
\hline$\partial^{2} \operatorname{var}\left(x_{t}\right) /\left.\partial \sigma_{e}^{2} \partial \sigma_{\varepsilon}^{2}\right|_{d i s}$ & 0.6159 & 0.9613 & 1.7029 & 3.7727 & 12.8032 \\
\hline
\end{tabular}

Second, under optimal discretion, even though an increase in opacity can reduce the volatility of inflation at low degrees of persistence, it can increase more significantly the volatility of the output gap. Thus, using the results reported in Table 1, we find that for the benchmark parameter values used in our simulation exercises, an increase in opacity would actually decrease social welfare measured by (17) for low degree of persistence of inflation shocks (i.e., $\rho=0.433$ ). In comparison, under optimal pre-commitment, using the same welfare measure, imperfect transparency always improves social welfare.

Third, Table 1 shows that, in absolute terms, the effects of opacity on the volatility of inflation and the output gap exponentially increase with the degree of persistence of inflation 
shocks. When a low initial degree of opacity is combined with a high degree of persistence, an increase in opacity could significantly increase the social welfare.

\subsection{Effects of opacity on macroeconomic dynamics}

We have previously shown that decreased transparency accelerates the convergence of inflation expectations both under optimal discretion and optimal pre-commitment in a timeless perspective. Before discussing the dynamic adjustment of current inflation and output gap, we compare the effects of opacity on the dynamics of inflation expectations across the two policy regimes. We compare the acceleration of convergence first in absolute terms and then in relative terms.

Comparing (36) with (20) clearly shows that $\frac{\partial \mathrm{E}_{t}\left(J_{2}\right)}{\partial \sigma_{\varepsilon}^{2}}>\frac{\partial \mathrm{E}_{t}(\Lambda)}{\partial \sigma_{\varepsilon}^{2}}$. This implies that opacity accelerates more the convergence of inflation expectations to their equilibrium level under pre-commitment than under discretion. The pre-commitment better anchors inflation expectations through the introduction of a certain degree of dependence of inflations expectations on the past output gap, allowing hence opacity to make a larger impact on the dynamic adjustment of inflation expectations than under discretion.

The above comparison in absolute terms does not take into account the fact that the initial speeds of convergence under these regimes are different. Comparing the opacity elasticity of eigenvalues associated with the dynamic adjustment of inflation expectations, we observe that an increase in opacity has a larger effect in relative terms on the convergence of inflation expectations under pre-commitment than under discretion if the initial degree of opacity is sufficiently low, i.e.,

$$
\sigma_{\varepsilon}^{2}<\frac{\lambda^{3}}{1+\lambda}\left(\frac{2-\beta}{2 \delta^{2}}-\frac{1}{\lambda}\right)
$$


Given that $\delta$ is small, the central bank must be very conservative by assigning a very small weight (i.e. very low $\lambda$ ) to the output-gap stabilization for the right hand of (38) to be negative. On the contrary, if $\lambda$ is such that condition (38) is invalid, we then have to reject the case where inflation expectations adjust more rapidly in relative terms under precommitment than under discretion. In this case, as $\lambda$ is also the upper bound for the degree of opacity, this will reduce the possibility of any significant effect of opacity on the convergence of inflation expectations under these two policy regimes.

For a given preference shock, the dynamic adjustments of current inflation and output gap similarly depend on inflation expectations. The comparison of the effects of opacity through this channel on their dynamics across the two policy regimes do not straightforwardly lead to clear-cut conditions. Some simulation exercises show that generally, impacted by imperfect transparency, the speed of convergence of expected and current inflation and the output gap are largely high under optimal pre-commitment than under optimal discretion (Figure 4).

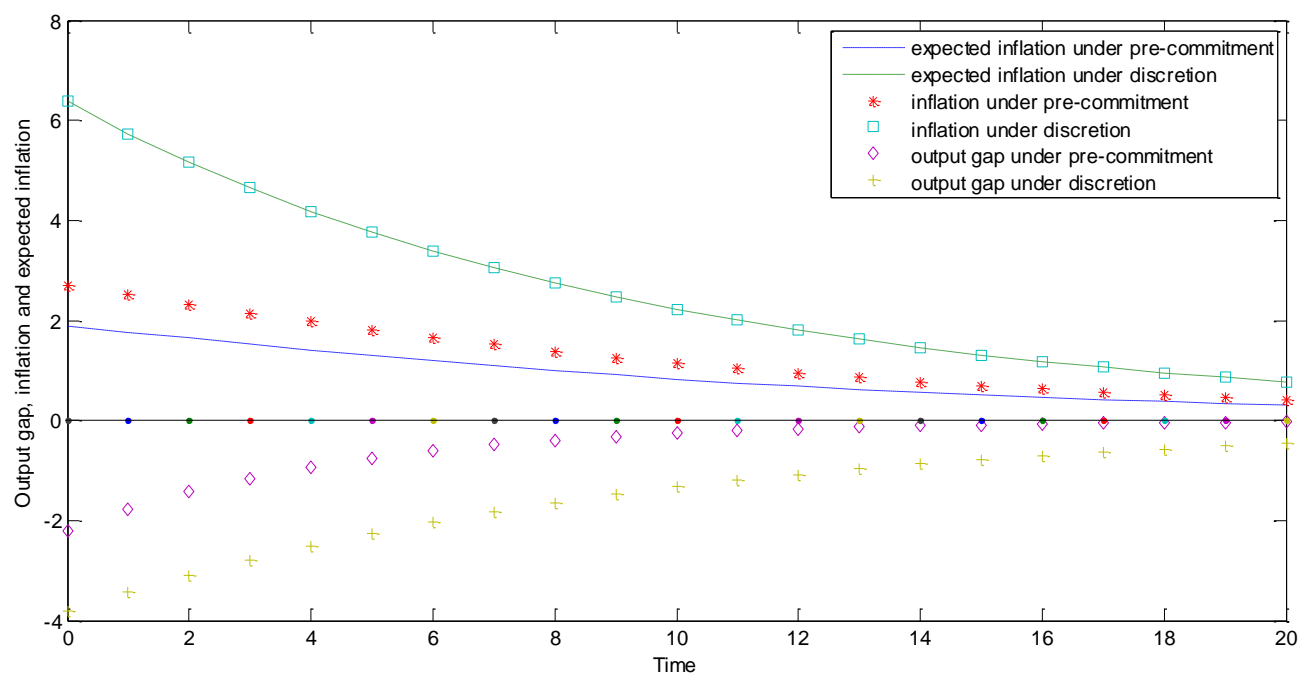

Figure 4: Comparison of the effects of imperfect transparency on average impulse responses of inflation expectations, inflation and the output gap under two policy regimes following a one-percent inflation shock for $\beta=0.99, \lambda=0.5, \delta=0.08, \lambda=0.5$, and $\rho=0.90$.

\section{Conclusions}


In this paper, we have examined the issue of political transparency in a forward-looking New Keynesian model by considering the static and dynamic effects of the uncertainty affecting the weights that the central bank assigns to inflation and output-gap stabilization. The effects of imperfect transparency vary significantly across policy regimes and are greatly dependent on the degree of persistence of inflation shocks.

Under optimal discretion, in the case where the shocks are serially uncorrelated, an increase in central bank opacity does not affect inflation expectations and hence has no effect on the level of inflation and the output gap through this channel, but reduces the average reaction of inflation and increases that of the output gap to inflation shocks through the policy rule channel, i.e., the direct effect of the central bank's preference shocks. It will decrease the volatility of inflation and will increase the volatility of the output gap if the output-gap elasticity of inflation is sufficiently low with respect to the average weight assigned by the central bank to the output-gap target. This is generally true given that the output-gap elasticity of inflation is quite small in the New Keynesian Phillips curve.

In the event of serially correlated inflation shocks, an increase in the persistence of inflation shocks reinforces the attenuation effects of central bank opacity on inflation and the output gap through the inflation expectations channel. On the other hand, higher persistence of inflation shocks will reduce (reinforce) the attenuation (amplification) effect of opacity through the policy rule channel on the average reaction of inflation (the output gap) to inflation shocks. On balance, when the persistence of inflation shocks is high, imperfect transparency could significantly improve social welfare if the weight assigned by the society to output-gap stabilization is relatively low.

Under optimal pre-commitment in a timeless perspective, a decrease in transparency reduces the dependence of inflation on the past output gap and increases that of the output gap 
if the weight assigned by the central bank to output-gap stabilization is relatively low. It reduces the sensitivity of inflation and the output gap to inflation shocks as under a discretionary policy regime. Optimal pre-commitment allows for larger attenuation effects of imperfect transparency on the average reaction of inflation to inflation shocks than under discretion when the degree of persistence is relatively low. In contrast, the amplification effect of opacity on the average reaction of the output gap is always smaller under pre-commitment than under discretion. Therefore, imperfect transparency under pre-commitment is more likely to improve social welfare by reducing the volatility of inflation more than under optimal discretion, except for very high degree of persistence of inflation shocks, and by increasing much less the volatility of the output gap than under discretion whatever are the initial degrees of opacity and inflation persistence.

Finally, imperfect transparency has similar dynamic effects across policy regimes. More central bank opacity does not modify the dynamic stability nature of the equilibrium but will accelerate the speed of convergence of inflation expectations. Imperfect transparency clearly accelerates through this channel, for a given preference shock, the speed of convergence of inflation and the output gap to their equilibrium levels compared with the benchmark of full transparency. These effects are to some extent mitigated by the direct effects of central bank's idiosyncratic preference shocks which accelerate the average dynamic adjustment of inflation but amplify the average divergence of the output gap from its equilibrium value. On balance, it is more probable under pre-commitment than under discretion that greater central bank opacity could improve social welfare in dynamic terms if the relative weight assigned by the society to output-gap stabilization is low. 


\section{References:}

Beetsma, R.M.W.J., and H. Jensen (2003), "Why money talks and wealth wispers: Monetary uncertainty and mystique. A comment," Journal of Money, Credit, and Banking 35(1), 129-136.

Blanchard, O. J., and C. M. Khan (1980), "The Solution of Linear Difference Models Under Rational Expectations," Econometrica 48, 1305-1310.

Blinder, Alan S., Michael Ehrmann, Marcel Fratzscher, Jakob De Haan, and David-Jan Jansen (2008), “Central bank communication and monetary policy: A survey of theory and evidence," Journal of Economic Literature 46 (4), 910-945.

Brainard, William C. (1967), "Uncertainty and the effectiveness of policy," American Economic Review 57(2), $411-425$

Ciccarone, Giuseppe, Enrico Marchetti, and Giovanni Di Bartolomeo (2007), “Unions, fiscal policy and central bank transparency," The Manchester School 75(5), 617-633.

Ciccarone, Giuseppe, and Enrico Marchetti (2009), "Revisiting the role of multiplicative uncertainty in a model without inflationary bias," Economics Letters 104(1), 37-39.

Clarida, R., Gali J., and Gertler M. (1999), "The science of monetary policy: a new Keynesian Perspective," Journal of Economic Literature 37(4), 1661-1707.

Crowe, Christopher, and Ellen Meade (2008), “Central bank independence and transparency: Evolution and effectiveness," European Journal of Political Economy 24(4), 763-777.

Cukierman, Alex (2002), “Are Contemporary Central Banks Transparent About Economic Models and Objectives and What Difference Does It Make?" The Federal Reserve Bank of St. Louis Review 84 (4), 1536.

Cukierman, Alex (2009), “The limits of transparency,” Economic Notes 38(1/2), 1-37.

Cukierman, Alex, and Allan H. Meltzer (1986), “A Theory of Ambiguity, Credibility, and Inflation under Discretion and Asymmetric Information,” Econometrica 54(5), 1099-1028.

Dai, Meixing, and Moïse Sidiropoulos (2011), "Monetary and fiscal policy interactions with central bank transparency and public investment," Research in Economics 65(3), 195-208.

Dai, Meixing, and Eleftherios Spyromitros (2010), “Accountability and Transparency about Central Bank Preferences for Model Robustness,” Scottish Journal of Political Economy,57(2), 212-237.

Dai, Meixing, and Eleftherios Spyromitros (2012), "Inflation contract, central bank transparency and model uncertainty," forthcoming in Economic Modelling. 
Demertzis, Maria, A. Hughes Hallet (2007), “Central Bank Transparency in Theory and Practice,” Journal of Macroeconomics 29(4), 760-789.

Dincer, Nergiz, and Barry Eichengreen (2007), "Central Bank Transparency: Where, Why and with What Effects?" NBER Working Paper No. 13003, March 2007.

Dincer, Nergiz, and Barry Eichengreen (2010), "Central bank transparency: causes, consequences and updates," Theoretical Inquiries in Law 11(1), Article 5.

Eijffinger, Sylvester C. W., and Mewael F. Tesfaselassie (2007), “Central Bank Forecasts and Disclosure Policy: Why it Pays to be Optimistic," European Journal of Political Economy 23(1), 30-50.

Eijffinger, Sylvester C. W., Marco Hoeberichts, Eric Schaling (2000), "Why Money Talks and Wealth Whispers: Monetary Uncertainty and Mystique," Journal of Money, Credit and Banking 32(2), 218-235.

Eijffinger, S.C.W., and C. van der Cruijsen (2010), "The Economic Impact of Central Bank Transparency: A Survey,” in: P. Siklos, M. Bohl and M. Wohar (eds.), Challenges in central banking: The present institutional environment and the forces affecting the conduct of monetary policy, Cambridge University Press, 261-319.

Faust, J., and L. E. O. Svensson (2001), “Transparency and Credibility: Monetary Policy with Unobservable Goals,” International Economic Review 42(2), 369-407. Galí, Jordi, and Mark Gertler (1999), “Inflation Dynamics: A Structural Econometric Analysis,” Journal of Monetary Economics 44(2), 195-222.

Geraats, Petra (2002), “Central Bank Transparency,” The Economic Journal 112, 532-565.

Geraats, Petra (2009), “Trends in monetary policy transparency,” International Finance 12(2), 235-268.

Grüner, Hans Peter (2002), "How Much Should Central Banks Talk? A New Argument”, Economics Letters $77(2), 195-198$.

Hefeker, Carsten, and Blandine Zimmer (2011a), "The optimal choice of central bank independence and conservatism under uncertainty," Journal of Macroeconomics 33(4), 595-606.

Hefeker, Carsten, and Blandine Zimmer (2011b), "Uncertainty and fiscal policy in an asymmetric monetary union," Open Economies Review 22(1), 163-178.

Hughes-Hallett, A., and Viegi, N. (2003), "Imperfect transparency and the strategic use of information in monetary policy: An ever present temptation for central bankers," The Manchester School 71(5), 498-520.

Jensen, Henrik (2002), “Optimal Degrees of Transparency in Monetary Policymaking,” Scandinavian Journal of Economics 104(3), 399-422.

King, Robert G., and Mark W. Watson (1998), “The Solution of Singular Linear Difference Systems under Rational Expectations," International Economic Review 39(4), 1015-26. 
McCallum, B. T. (1983), "On Nonuniqueness in Linear Rational Expectations Models: An Attempt at Perspective,” Journal of Monetary Economics 11(2), 139-168.

McCallum, B. T., and Nelson, E. (2004), "Timeless Perspective vs. Discretionary Monetary Policy in Forwardlooking Models," Federal Reserve Bank of St. Louis Review 86, 43-56.

Nolan, C., and E. Schaling (1998), "Monetary Policy Uncertainty and Inflation: The Role of Central Bank Accountability,” De Economist 146(4), 585-602.

Qin, Li, Moïse Sidiropoulos, and Eleftherios Spyromitros (2010), "Robust Monetary Policy with Uncertain Central Bank Preferences,” Bulletin of Economic Research 62(2), 197-208.

Roberts, John (1995), "New Keynesian Economics and the Phillips Curve," Journal of Money, Credit and Banking 27 (4), Part 1, 975-984.

Sorensen, J. R. (1991), "Political uncertainty and macroeconomic performance," Economics Letters 37(4), 377381.

Spyromitros Eleftherios and Blandine Zimmer (2006), "Monetary Accommodation and Unemployment: Why Central Bank Transparency Matters,” Economics Letters 102(2), 119-121.

Spyromitros, Eleftherios and Sukriye Tuysuz (2012), "Do Monetary Policy Transparency, Independence and Credibility Enhance Macro-financial Stability?” International Journal of Economics and Finance 4(4), 44-54. van der Cruijsen, Carin A.B., Sylvester C.W. Eijffinger, and Lex H. Hoogduin (2010), “Optimal central bank transparency," Journal of International Money and Finance 29(8): 1482-1507.

Walsh, Carl E. (2003a), “Accountability, Transparency, and Inflation Targeting,” Journal of Money, Credit, and Banking 35(5), 829-849.

Walsh, Carl E. (2003b), Monetary Theory and Policy, the MIT Press.

Walsh, Carl E. (2007a), Optimal Economic Transparency, International Journal of Central Banking, 3(1): 5-36. Walsh, Carl E. (2007b), “Transparency, Flexibility, and Inflation Targeting,” Central Banking, Analysis, and Economic Policies Book Series, in: Frederic S. Miskin \& Klaus Schmidt-Hebbel \& Norman Loayza (Series Editor) \& Klaus Schmidt-Hebbel (Se (ed.), Monetary Policy under Inflation Targeting, edition 1, volume 11, chapter 7, 227-263, Central Bank of Chile.

Westelius, Niklas J. (2009), “Imperfect transparency and shifts in the central bank's output gap target,” Journal of Economic Dynamics and Control 33(4), 985-996.

Woodford, M., (1999), “Commentary: How Should Monetary Policy Be Conducted in an Era of Price Stability?" in Federal Reserve Bank of Kansas City (ed.), New Challenges for Monetary Policy, Kansas City. 


\section{Documents de travail du BETA}

2012-01 Unanticipated vs. Anticipated Tax Reforms in a Two-Sector Open Economy Olivier CARDI, Romain RESTOUT, janvier 2012.

2012-02 University Technology Transfer: How (in-)efficient are French universities? Claudia CURI, Cinzia DARAIO, Patrick LLERENA, janvier 2012.

2012-03 L'autorité de la concurrence doit-elle, dans le cadre de sa fonction consultative disposer de toutes les libertés?

Marc DESCHAMPS, juin 2012.

2012-04 Currency devaluation with dual labor market: Which perspectives for the Euro Zone? Amélie BARBIER-GAUCHARD, Francesco DE PALMA, Giuseppe DIANA, juin 2012.

2012-05 The Routinization of Creativity: Lessons from the Case of a video-game Creative Powerhouse.

Patrick COHENDET, Patrick LLERENA, Laurent SIMON, juin 2012.

2012-06 Status-seeking and economic growth: the Barro model revisited.

Thi Kim Cuong PHAM, juin 2012.

2012-07 Considerations on partially identified regression models.

David CERQUERA, François LAISNEY, Hannes ULLRICH, juillet 2012.

2012-08 Static and Dynamic Effectsof Central Bank Transparency

Meixing DAI, juillet 2012.

La présente liste ne comprend que les Documents de Travail publiés à partir du $1^{\mathrm{er}}$ janvier 2012. La liste complète peut être donnée sur demande.

This list contains the Working Papers written after January 2012, 1rst. The complet list is available upon request. 